\title{
Nail Psoriasis: A Review of Effective Therapies and Recommendations for Management
}

\author{
Edward Hadeler (D) - Megan Mosca • Julie Hong • Nicholas Brownstone •
}

Tina Bhutani · Wilson Liao

Received: February 18, 2021 / Published online: May 12, 2021

(C) The Author(s) 2021

\section{ABSTRACT}

Nail psoriasis has a prevalence that ranges from 10 to $82 \%$ and can significantly impact the quality of life of patients. Nail psoriasis is one of the most challenging areas to treat, and multiple therapies have been explored. Topical and injectable therapies are recommended for fewnail disease. Systemic therapies, including biologics, can be considered for patients with multiple and resistant nail disease, impaired quality of life, and severe skin and joint involvement, due to their long-term efficacy. Although outcome data are difficult to compare, interleukin (IL)-17 inhibitors may have superior short-term efficacy when compared to IL-23 inhibitors and tumor necrosis factor (TNF)-alpha inhibitors, although long-term efficacy is similar to TNF-alpha inhibitors. IL-23 inhibitors and TNF-alpha inhibitors have a similar efficacy for nail psoriasis.

Keywords: Nail; Nails; Nail psoriasis; Special site; Biologic; Systemic; Topical; Injectable; Laser

E. Hadeler $(\bowtie) \cdot$ M. Mosca $\cdot$ J. Hong .

N. Brownstone $\cdot$ T. Bhutani · W. Liao

Department of Dermatology, Psoriasis and Skin Treatment Center, University of California San Francisco, 515 Spruce Street, San Francisco, CA 94118, USA

e-mail: Edward.hadeler@ucsf.edu

\section{Key Summary Points}

Nail manifestations of psoriasis are detrimental to patient's quality of life (QoL) and are a prognostic factor for more severe skin disease and comorbidities, such as psoriatic arthritis

First-line treatments for few-nail disease ( $\leq$ 3 nails involved) includes topicals and intralesional injections

When disease involves $>3$ nails, has extensive cutaneous and joint involvement, and has a significant impact on QoL, systemic therapies should be considered

Certain interleukin (IL)-17 inhibitors have been shown to be superior to IL-12/23 inhibitors (brodalumab vs. ustekinumab) and have superior short-term efficacy in comparison to IL-23 inhibitors (ixekizumab vs. guselkumab) and tumor necrosis factor (TNF)-alpha inhibitors (ixekizumab vs. etanercept), though their long-term efficacy is similar to TNF-alpha inhibitors

Certain TNF-alpha inhibitors have similar efficacy to IL-23 inhibitors (adalimumab vs. guselkumab) 


\section{DIGITAL FEATURES}

This article is published with digital features including a summary slide, to facilitate understanding of the article. To view digital features for this article go to https://doi.org/10.6084/ m9.figshare.14320184.

\section{INTRODUCTION}

Involvement of the nails in psoriasis has been well defined as a factor with a detrimental effect on a psoriasis patient's quality of life (QoL). Studies have demonstrated psoriasis patients with nail involvement have a higher impairment of health-related QoL than psoriasis patients without nail involvement [1]. With a prevalence that ranges from 10 to $82 \%$ in patients with psoriasis [2], nail involvement is one of the most common special site manifestations of psoriasis. Nail psoriasis has many presentations, ranging from pitting, crumbling and loosening of the nail plate to oil drop discoloration and splinter hemorrhaging of the nail bed [3]. Of note, it is an independent prognostic factor for comorbidities such as psoriatic arthritis (PsA) and greater degrees of skin severity in plaque psoriasis [1,4]. Recent recommendations have been published on the management options of nail psoriasis [2]. However, several new studies on non-biologic as well as biologic therapies have been published in the interim. Here, we discuss the various therapies, including topicals, injectables, systemic, lasers, and complementary therapies, that have been explored for the treatment of nail psoriasis. We describe in detail the recent clinical trials that have evaluated their use and provide management recommendations.

\section{METHODS}

A literature search was conducted in PubMed and Embase in October 2020 using a combination of the terms 'nail' AND 'psoriasis.' Our initial search was filtered using the "clinical trial" filter in the PubMed and Embase search options. Additional searches were conducted using the terms 'secukinumab' OR 'brodalumab' with 'nail' AND 'psoriasis' since trials for these drugs did not appear on our original search. Only studies written in the English language were reviewed. All original prospective, retrospective studies, and nonexperimental descriptive studies were chosen for the purpose of this review. Comprehensive review articles were referenced to identify any additional studies that were missed during the initial searches. This search was replicated in March of 2021 to include articles published in the interim. A total of 67 original studies were reviewed in this article.

This article is based on previously conducted studies and does not contain any studies with human participants or animals performed by any of the authors.

\section{RESULTS}

\section{Topical and Local Injection Therapy}

Topical therapy represents one of the oldest and most well-studied treatment methods for nail psoriasis. Multiple medications have been studied, including calcipotriol ointment [5], anthralin therapy [6], 5-fluorouracil [7], tazarotene [8], cyclosporin [9], vitamin D analogue/corticosteroid formulations [10], and tacalcitol. [11] Local injection therapies include steroid injections $[10,12]$ and methotrexate injections [13-15]. Here, we first describe practical tips for the application of topical and injectable therapies before discussing studies that evaluated their efficacy.

The optimal pharmaceutical formulation of topical therapy is that of an ointment or solution [2]. Achieving optimal therapeutic concentrations of topical medications is challenging with nail psoriasis given the presence of the nail plate, which can serve as an impermeable physical barrier [16]. Therefore, identifying the exact anatomical location of psoriatic nail disease is key to determining how and where topical medications should be applied. When the nail matrix is involved, the topical medication should be applied to the proximal nail fold, just above the nail matrix, 
without occlusion. If the nail bed is involved, then the diseased nail should be trimmed as short as possible before topical medication is applied directly to the hyponychium, again without occlusion.

Rigopoulous et al. provide recommendations on the injection technique, recommending an optimal concentration of triamcinolone acetonide, the first-line injectable corticosteroid, of $5-10 \mathrm{mg} / \mathrm{mL}$, administered every $4-8$ weeks [2]. Intralesional steroid injection should be conducted under local block anesthesia. Clark et al. note that refrigerant spray applied before injection is well appreciated by patients [17]. A maximum of $0.1-0.5 \mathrm{~mL}$ can be injected in each quadrant of the nail unit and another $0.1-0.5 \mathrm{~mL}$ should be injected into the matrix. Location of the injection can vary based on the exact site of pathology [2]. Side effects of intralesional treatment vary according to the administered drug. For corticosteroid injections, predominant side effects include proximal nail fold hypopigmentation and atrophy [15]. For methotrexate, predominant side effects include pain and slight injection site discoloration.

First-line topical therapy options include superpotent topical steroids, such as clobetasol propionate [2] or calcipotriol (vitamin D analogue)/corticosteroid formulations. An open-label study conducted by Rigopoulos et al. in 2009 evaluated the efficacy of this formulation in 25 patients with nail psoriasis [10]. Patients were instructed to apply the ointment formulation once daily for 12 weeks on affected nails. At baseline the mean Nail Psoriasis Severity Index (NAPSI) score was $5.8 \pm 1.7$, and at the end of the study period it was $1.6 \pm 0.6$, representing a $72 \%$ improvement.

In the last 10 years, five randomized controlled trials (RCTs) have evaluated the use of topicals, either alone or in combination with corticosteroid injections, for the treatment of nail psoriasis. Recent trials have explored the use of varying concentrations of corticosteroids in a variety of formulations versus other topical agents $[18,19]$. In 2012, Nakamura et al. conducted a randomized trial comparing nail lacquer with clobetasol at concencentrations of $0.05,1$, and $8 \%$ [19]. In this study, patients received a treatment lacquer on the left hand with a base coat of nail lacquer control on the right hand, applied twice weekly for a total of 16 weeks. Clinical evaluation was performed by photographs and NAPSI score of both hands. The $8 \%$ clobetasol concentration showed a statistically significant greater clinical response compared to the other two groups [19].

In a controlled study conducted in 2013, Simone et al. evaluated the use of topical tacrolimus $0.1 \%$ ointment for the treatment of psoriatic nails for a total of 12 weeks [20]. At week 12 , there was a statistically significant improvement in NAPSI score absolute change observed in the hands that received treatment versus the hands that received the control ointment (NAPSI score: 13 vs. $3 ; p<0.0001$ ).

Kole et al. conducted a double-blind trial evaluating the efficacy of calcitriol ointment in comparison to betamethasone dipropionate ointment [18]. Ten adult patients were enrolled, and the primary endpoint was absolute reduction of target nail thickness. The results showed that patients treated with either betamethasone dipropionate or calcitriol ointment had reduced nail thickness, with no level of significance established between the two groups $(p=0.42)$. This study highlighted that calcitriol ointment may be as effective as betamethasone ointment.

In 2018, a study conducted by Saki et al. compared the therapeutic effects of triamcinolone acetonide iontophoresis (TI) and topical calcipotriol/betamethasone dipropionate. The results demonstrated that there was no difference between effects of TI versus topical therapy in terms of nail bed score $(p=0.356)$, matrix score $(p=0.137)$, and total NAPSI $(p=0.098)$ [21].

In 2019, a single-blind randomized control trial by Boontaveeyuwat et al. compared the efficacy of corticosteroid injections versus topicals in the treatment of nail psoriasis [22]. Using block randomization, the authors randomized the nails of the patients into three groups: fingernails received injection (Group A); fingernails received topical therapy (Group B); and control fingernails, with no therapy (Group C) . Ultimately, three nails were selected from each patient and randomly given the injection (A), topical therapy (B), or no treatment (C). 
Injections (triamcinolone $10 \mathrm{mg} / \mathrm{ml}$ ) were performed at baseline and at the second month if nails did not respond initially. Topical therapy (0.05\% clobetasol propionate) was applied at the proximal nail fold (for nail matrix disease) and hyponychium (for nail bed disease) of the target nail two times per day, without occlusion, for a total of 6 months. All nails were evaluated independently by two dermatologists. By the second month, there was a significant reduction in NAPSI score in the injection group compared to the control $(p=0.003)$. By the fourth month, there was a significantly greater reduction in NAPSI score for the injection group compared to the control $(p=0.003)$ and topical group $(p<0.001)$. However, by the sixth month, the difference between the injection group compared to the control and topical group had became nonsignificant.

Therapies involving injections directly to the nail have become attractive options given the side effects of oral/parenteral formulations of these medications. Mittal et al. observed the effects of intramatrical instillation of three medications, namely, methotrexate, triamcinolone, and cyclosporine. These authors concluded that methotrexate was superior given the low rate of adverse effects [14]. Subsequently, Grover et al. reported successful treatment of nail psoriasis with intralesional injections of methotrexate into the nail bed [15]. Recently, the use of intramatrical methotrexate in the treatment of nail psoriasis was evaluated in an uncontrolled prospective study involving 20 patients [13]. After administration of a ring block, $2.5 \mathrm{mg}$ intramatrical methotrexate was injected at each side of the nail at a point $2.5 \mathrm{~mm}$ proximal and lateral to the junction of the proximal and lateral nail folds. Injections were given weekly for 6 weeks. The mean NAPSI score was reduced significantly from 3.70 to 0.67 at 12 weeks $(p<0.001)$. The average total dose of methotrexate was 135 (range 60-300) mg. Adverse events (AEs) included pain at the injection site in two patients and acute paronychia in one patient. At the 1-year follow-up, there was no evidence of recurrence of nail psoriasis.

\section{Systemic Therapies}

In terms of systemic agents used to treat nail psoriasis, most data recorded to date are on adalimumab [23-27], which is also the only biologic therapy with efficacy data cited in the US Food and Drug Administration's package insert [28]. However, multiple other biologic and systemic therapies have been studied in the treatment of nail psoriasis, including apremilast [29-32], certolizumab [33, 34], etanercept [35-37], infliximab [35, 38, 39], guselkumab [40], ixekizumab [41-45], secukinumab [34, 46-48], ustekinumab [49-51], acitretin, [52] methotrexate [53, 54], cyclosporine [53], brodalumab [55, 56], golimumab [57], and tofacitinib $[58,59]$. Results of studies evaluating the efficacy of systemic agents in treating nail psoriasis are summarized in Table 1 . Some of these studies are discussed in the following sections.

\section{PDE-4 Inhibitors}

\section{Apremilast}

In 2016, the ESTEEM 1 and 2 phase III RCTs explored the use of apremilast in patients with difficult-to-treat areas, including nail psoriasis [29]. A total of 824 patients with nail psoriasis were randomized 2:1 to receive apremilast $30 \mathrm{mg}$ twice daily or placebo and at week 16, those on placebo were switched to apremilast, followed by a randomized withdrawal phase at week 32. At week 16, apremilast produced greater improvement in NAPSI index versus placebo in both studies [mean NAPSI percentage improvement of $22.5 \%$ vs. $-6.5 \%$ $(p<0.0001)$ and $29.0 \%$ vs. $7.1 \%(p=0.0052)$ for ESTEEM 1 and 2, respectively]. A negative percentage here implies a worsening in NAPSI. A significantly greater proportion of patients on apremilast achieved a NAPSI-50 score $(50 \%$ reduction from baseline in NAPSI score) at week 16 versus placebo $[33.3 \%$ vs. $14.9 \%$ $(p<0.00001) \quad$ and $\quad 44.6 \%$ vs. $18.7 \%$ $(p<0.00001)$ for ESTEEM 1 and 2, respectively].

Patients who received apremilast $30 \mathrm{mg}$ twice daily continued to show improvement at week 32 with a mean NAPSI percentage improvement of $43.6 \%$ and $60.0 \%$ in ESTEEM 1 


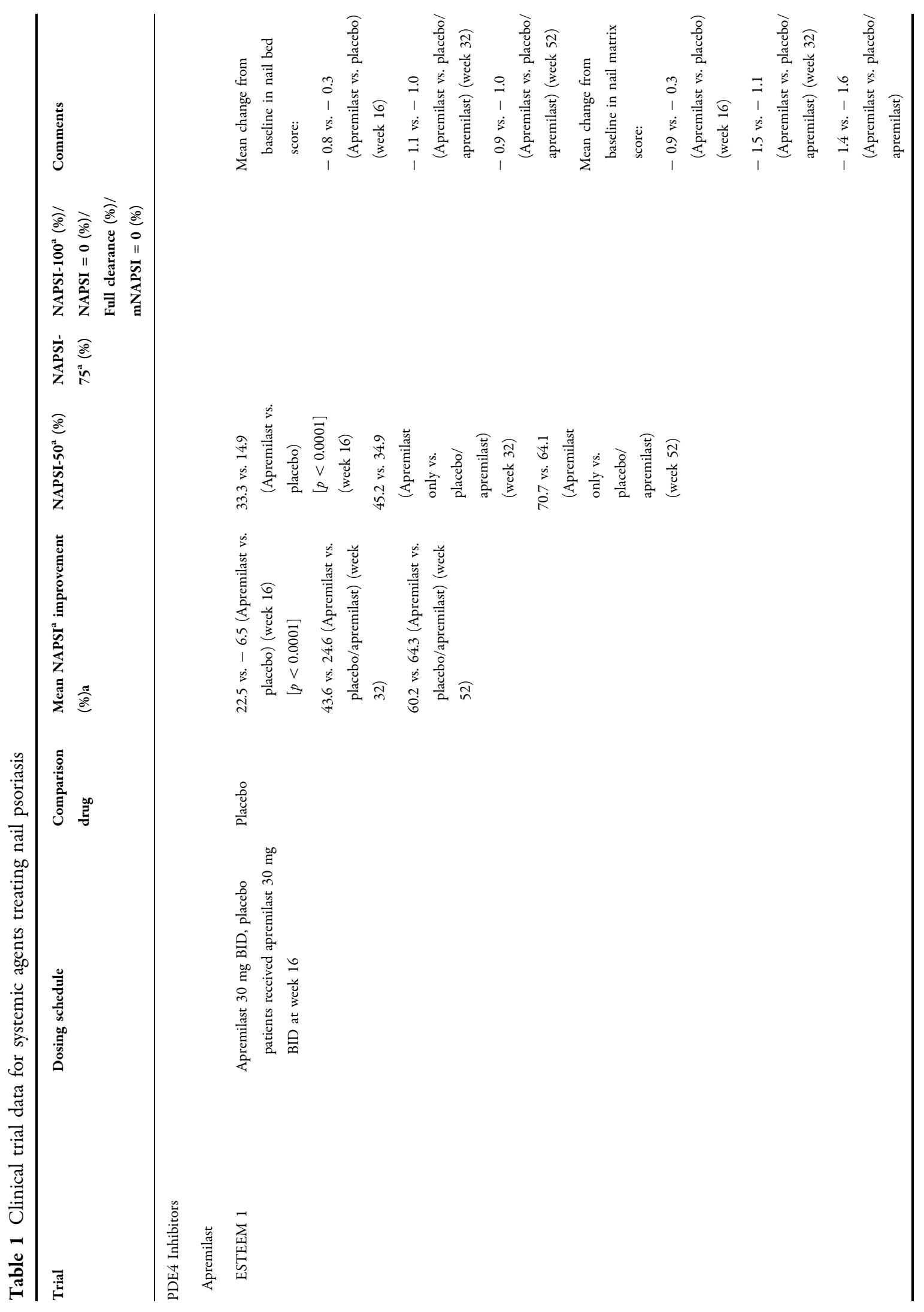




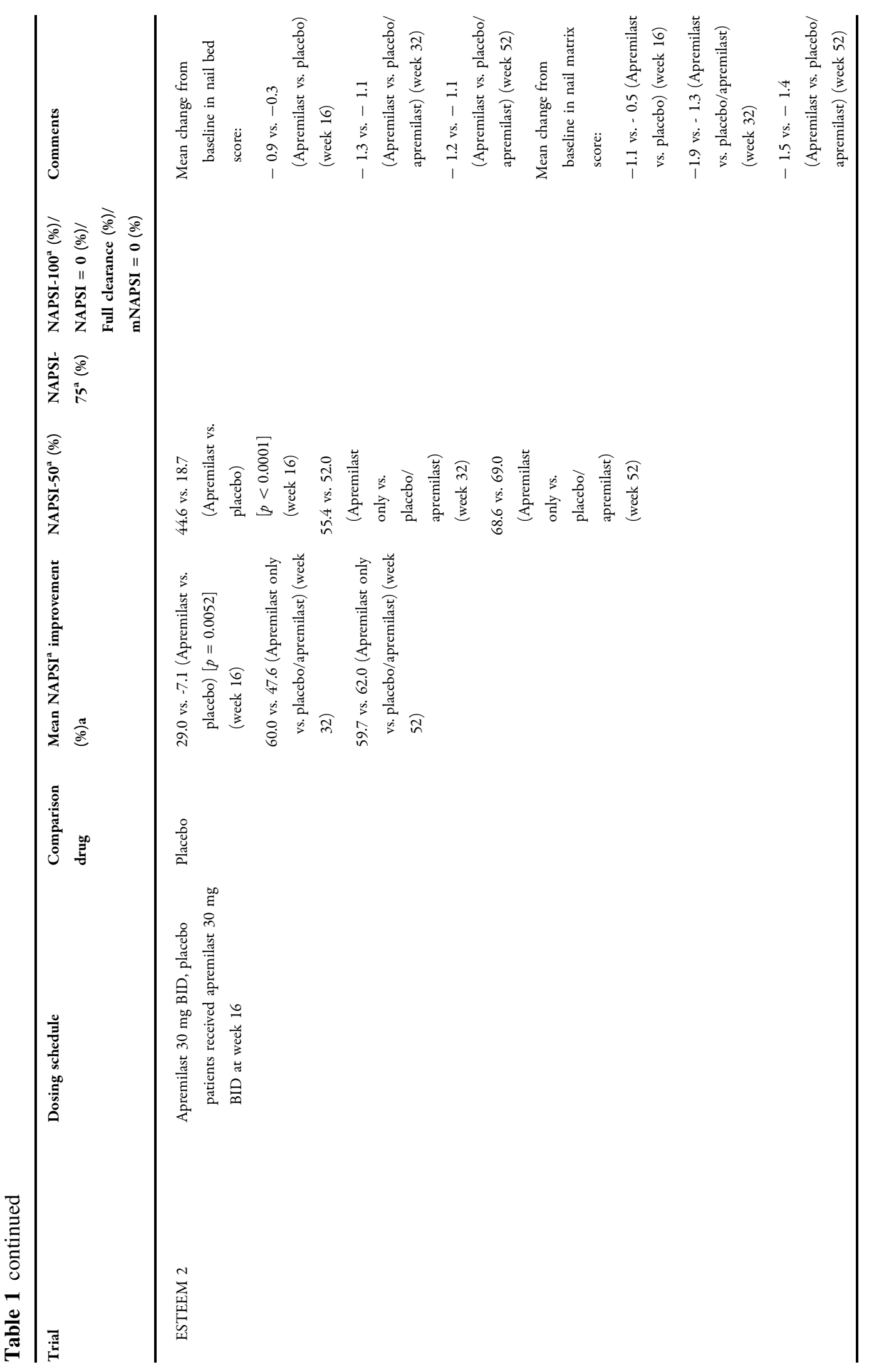




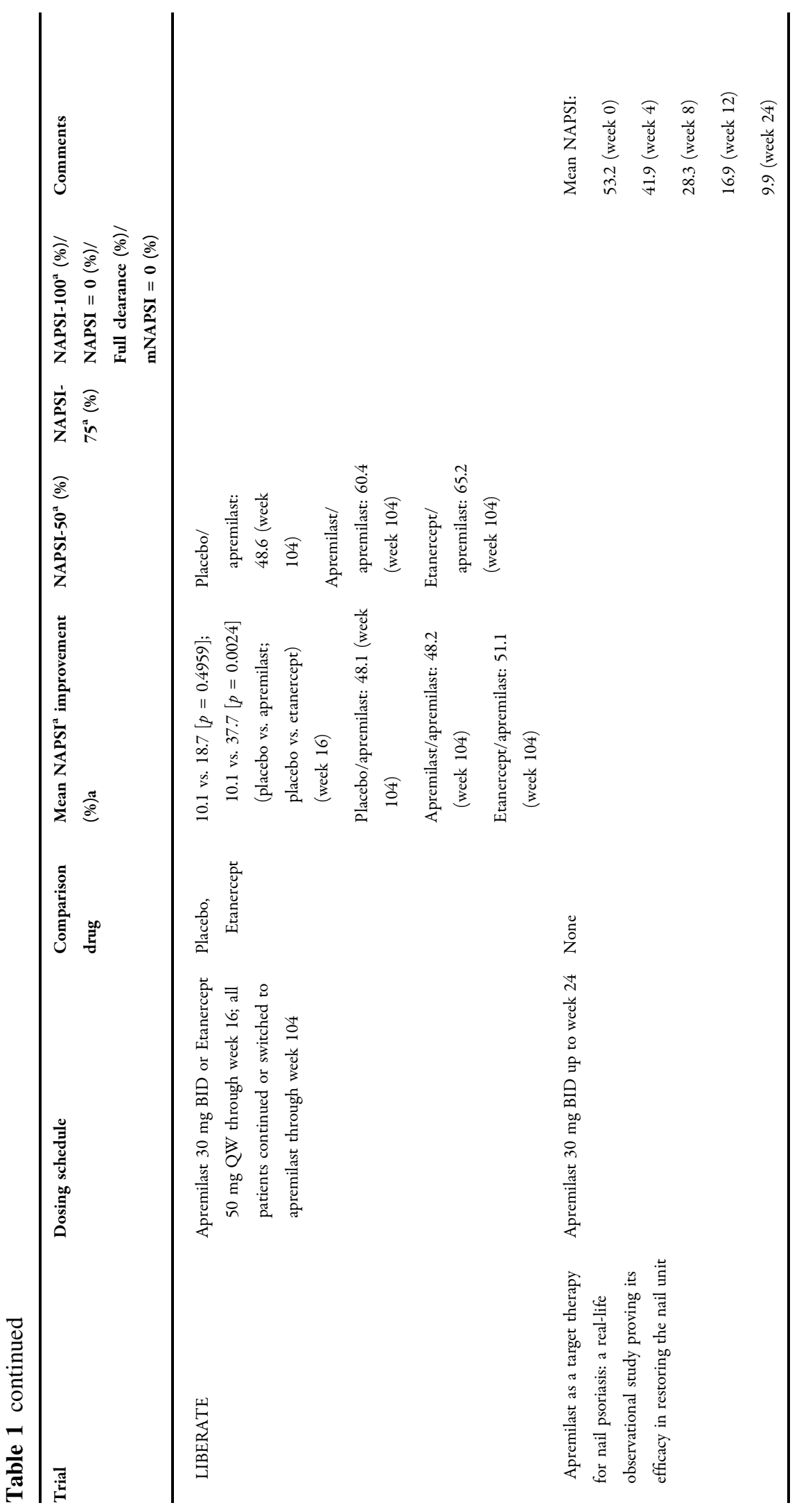




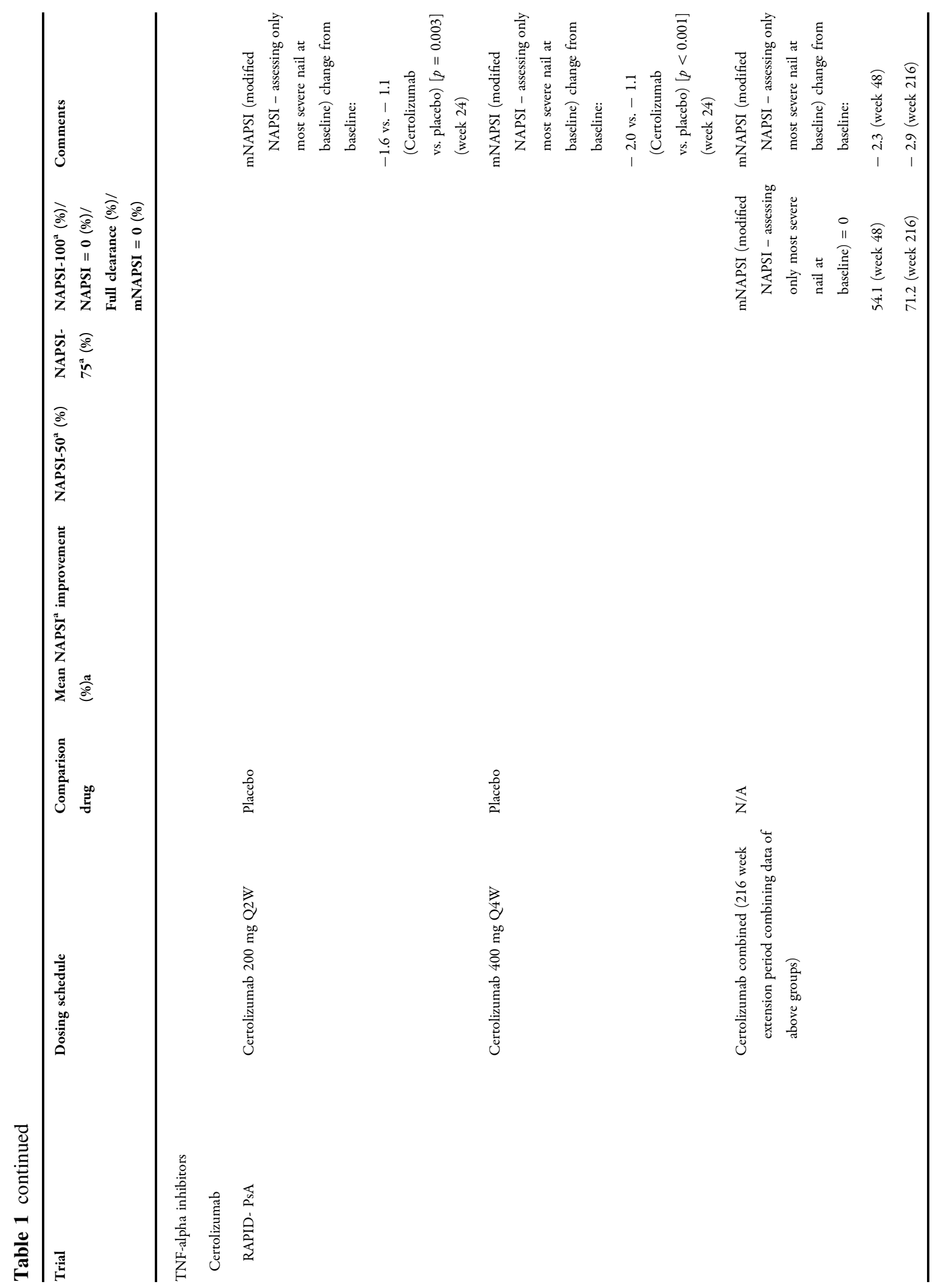




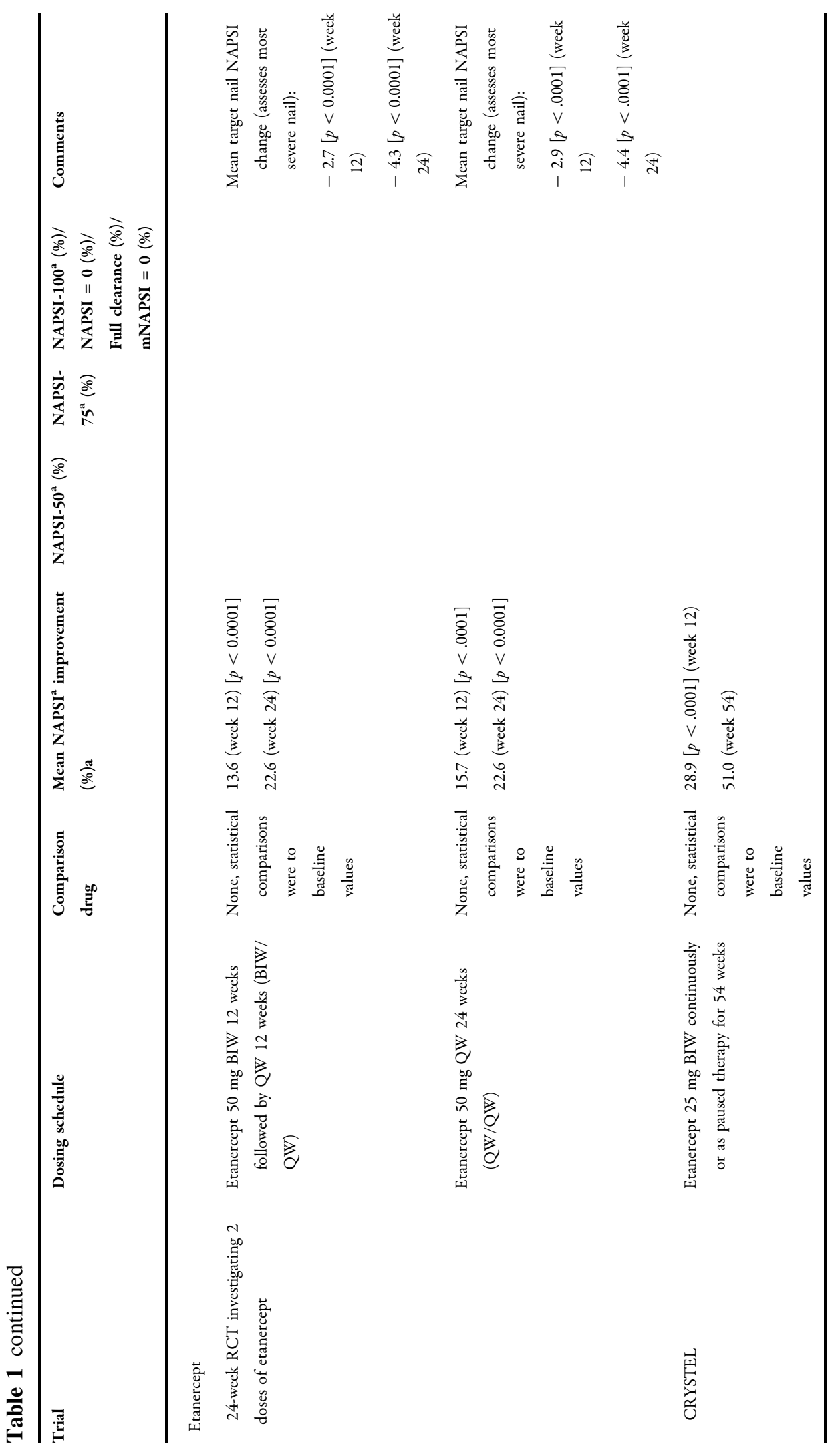




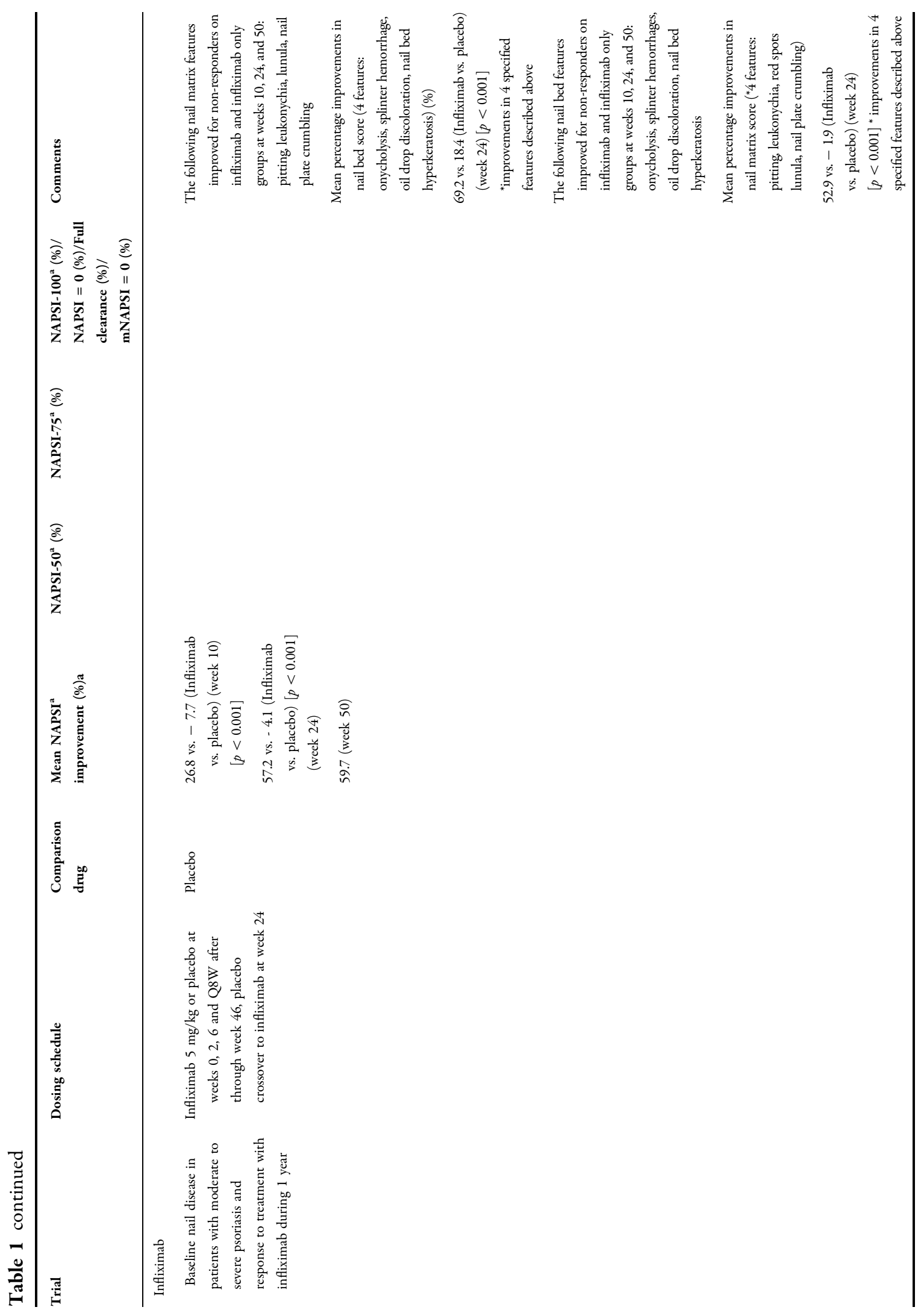




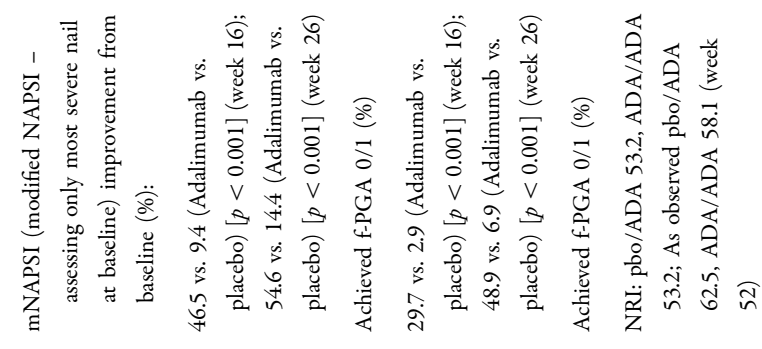

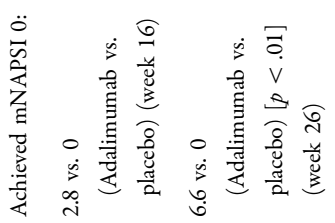

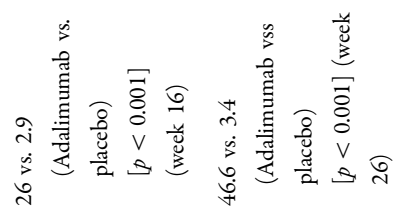

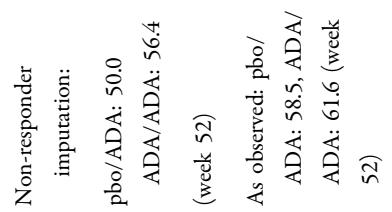

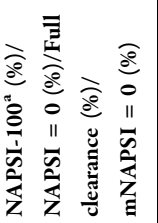

$\frac{\widehat{a}}{i n}$

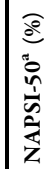

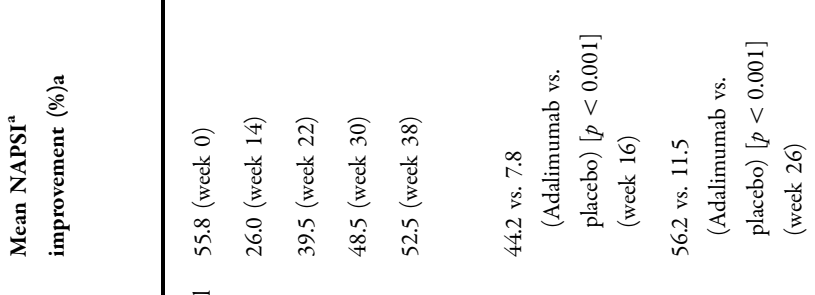

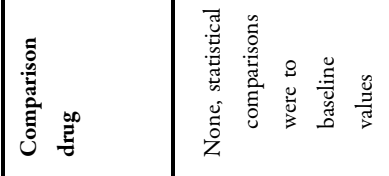

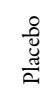

そั

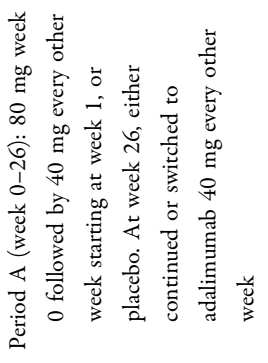

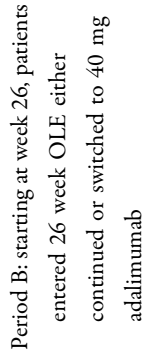

|

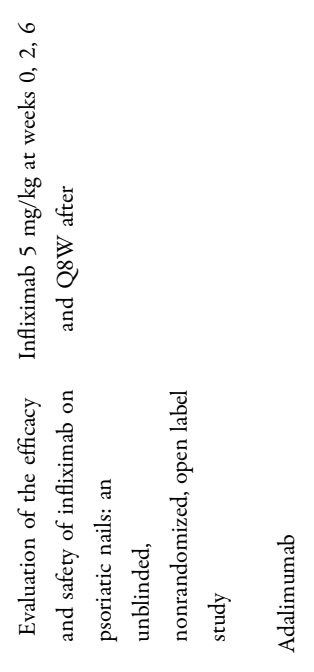

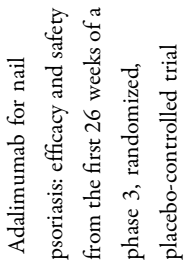

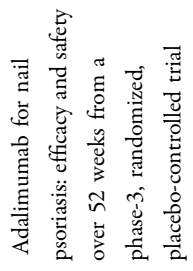




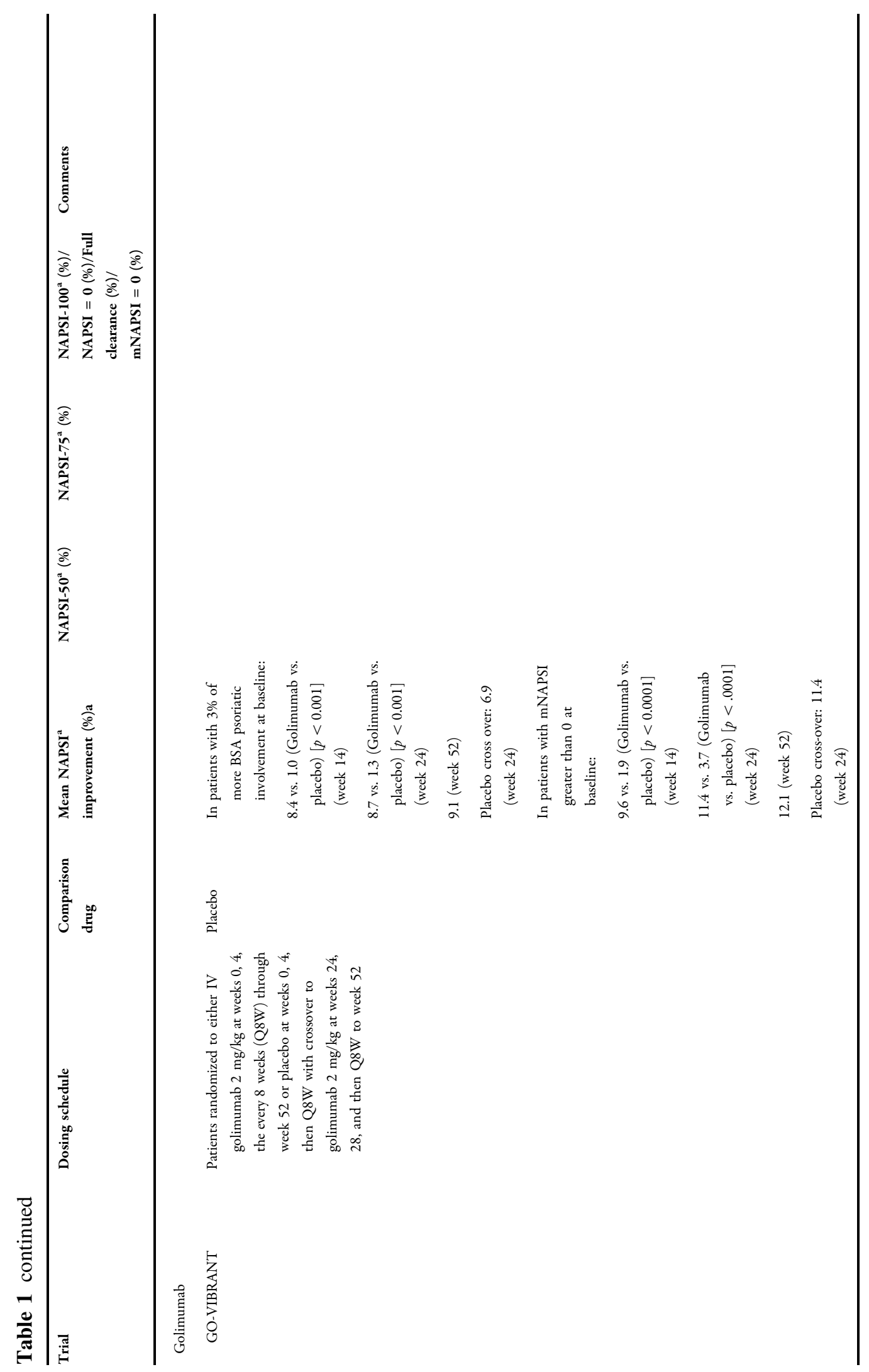




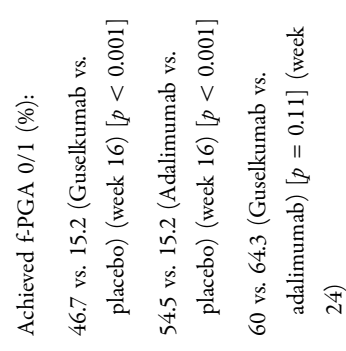

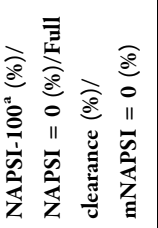

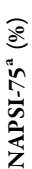

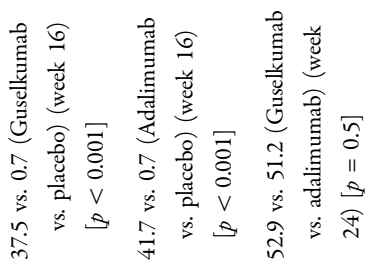

离

告

है

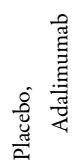

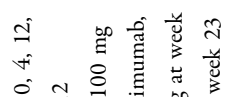

$\therefore$ 글

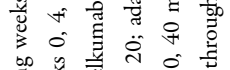

of

\&

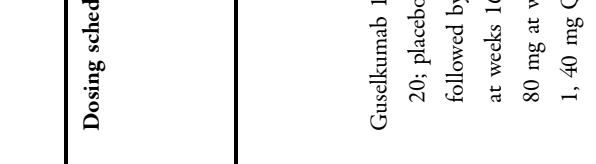

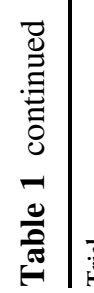

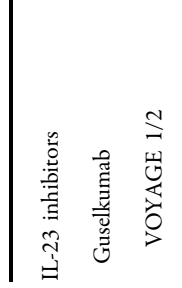




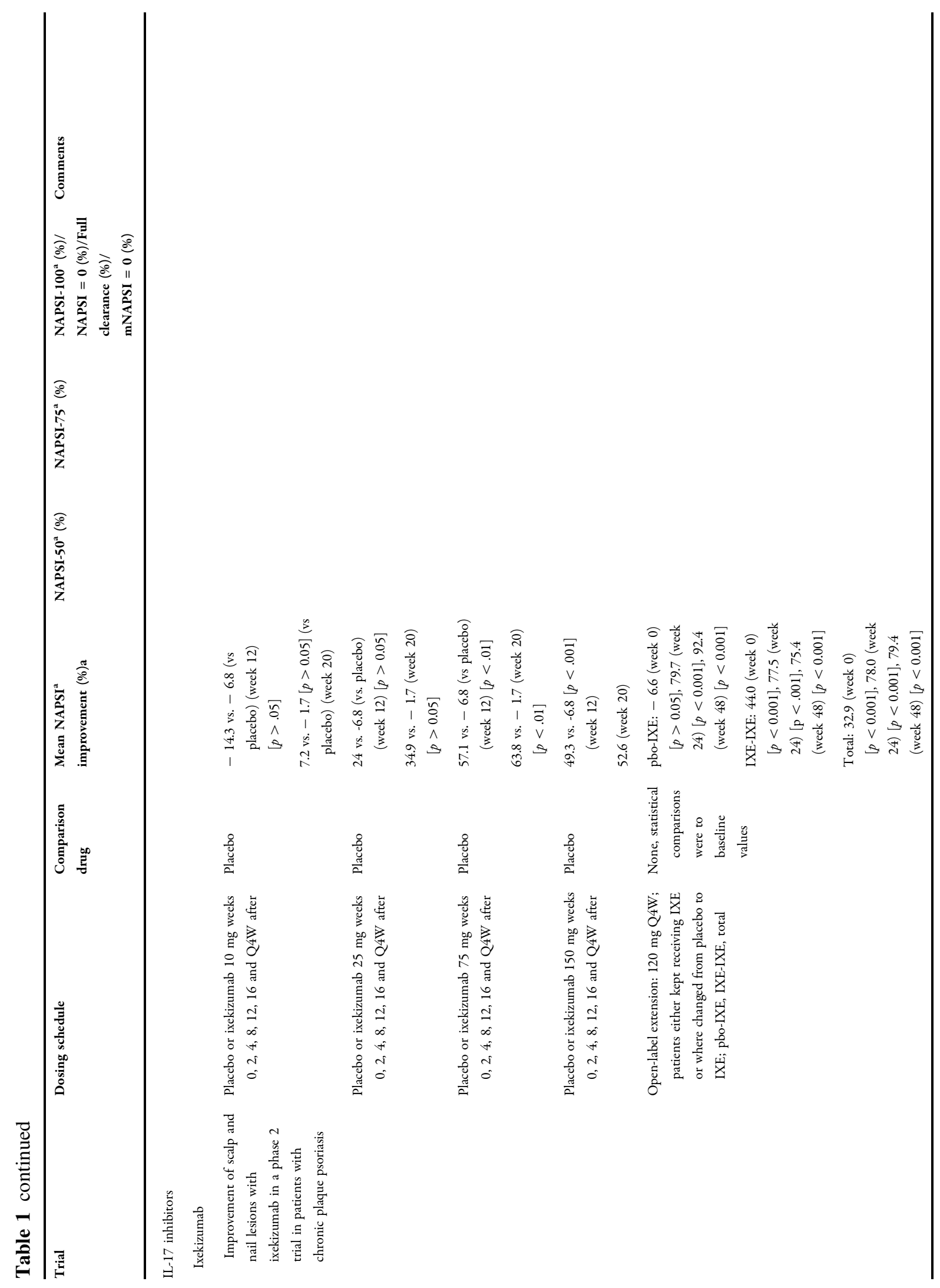




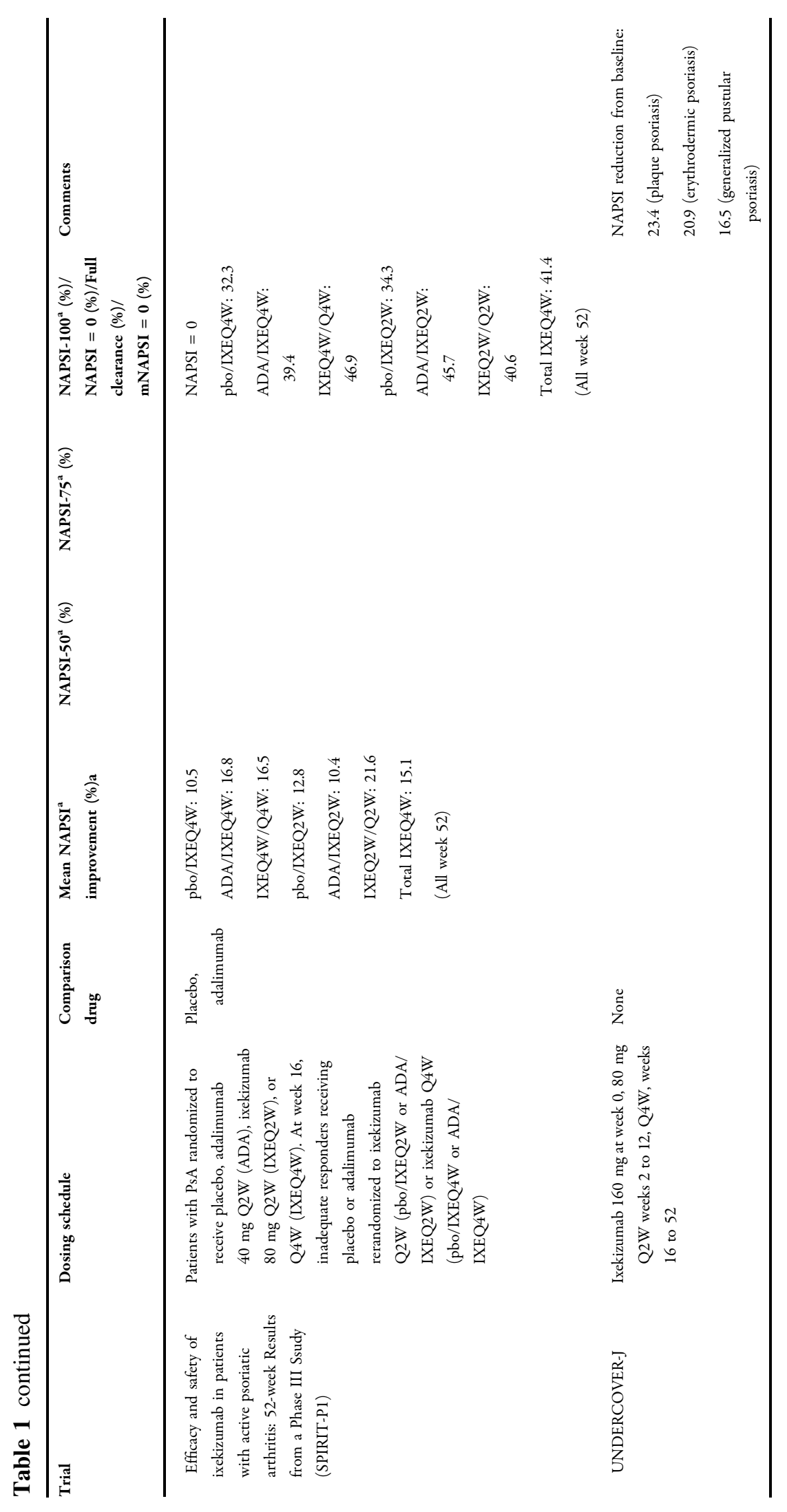




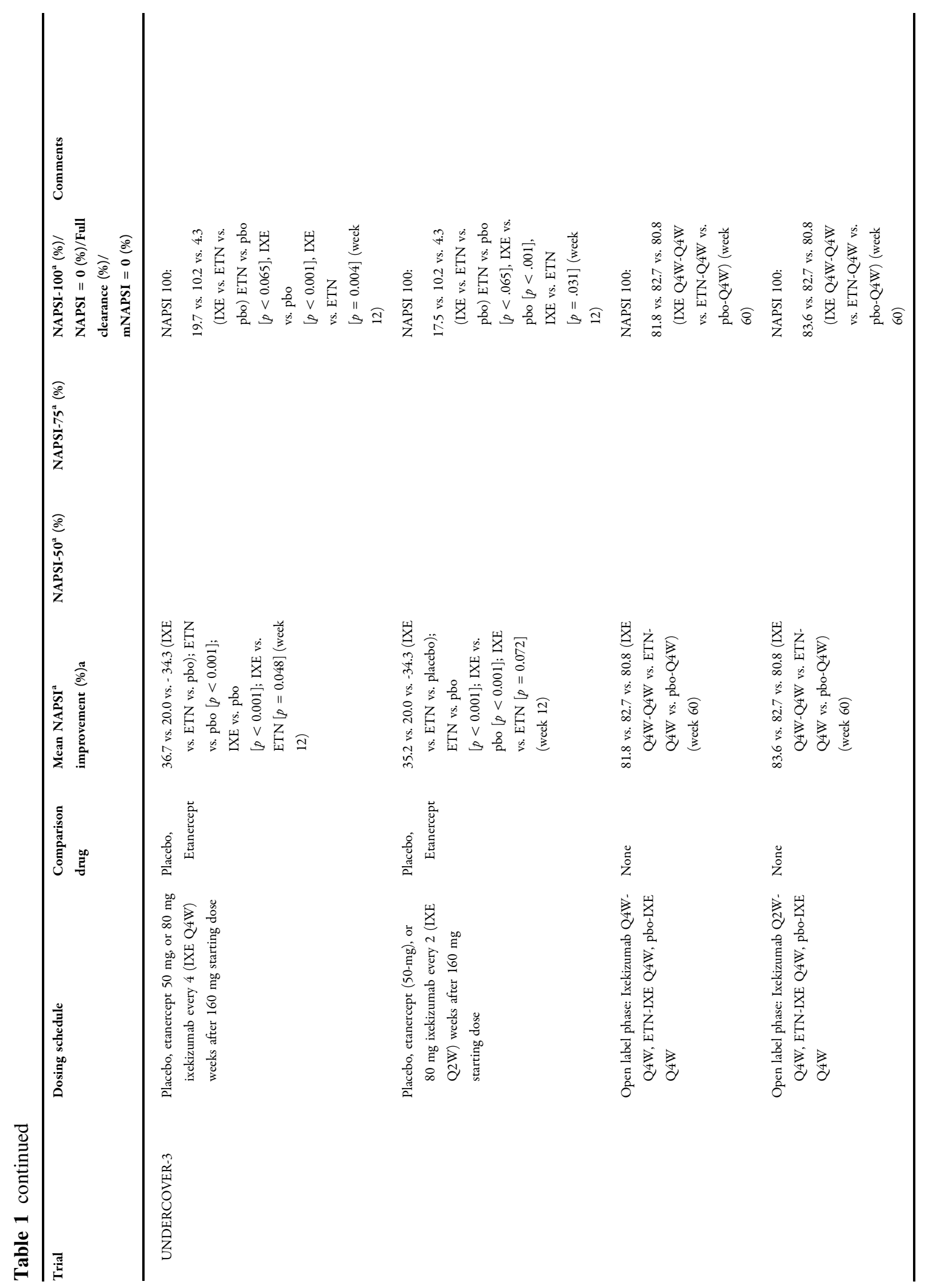




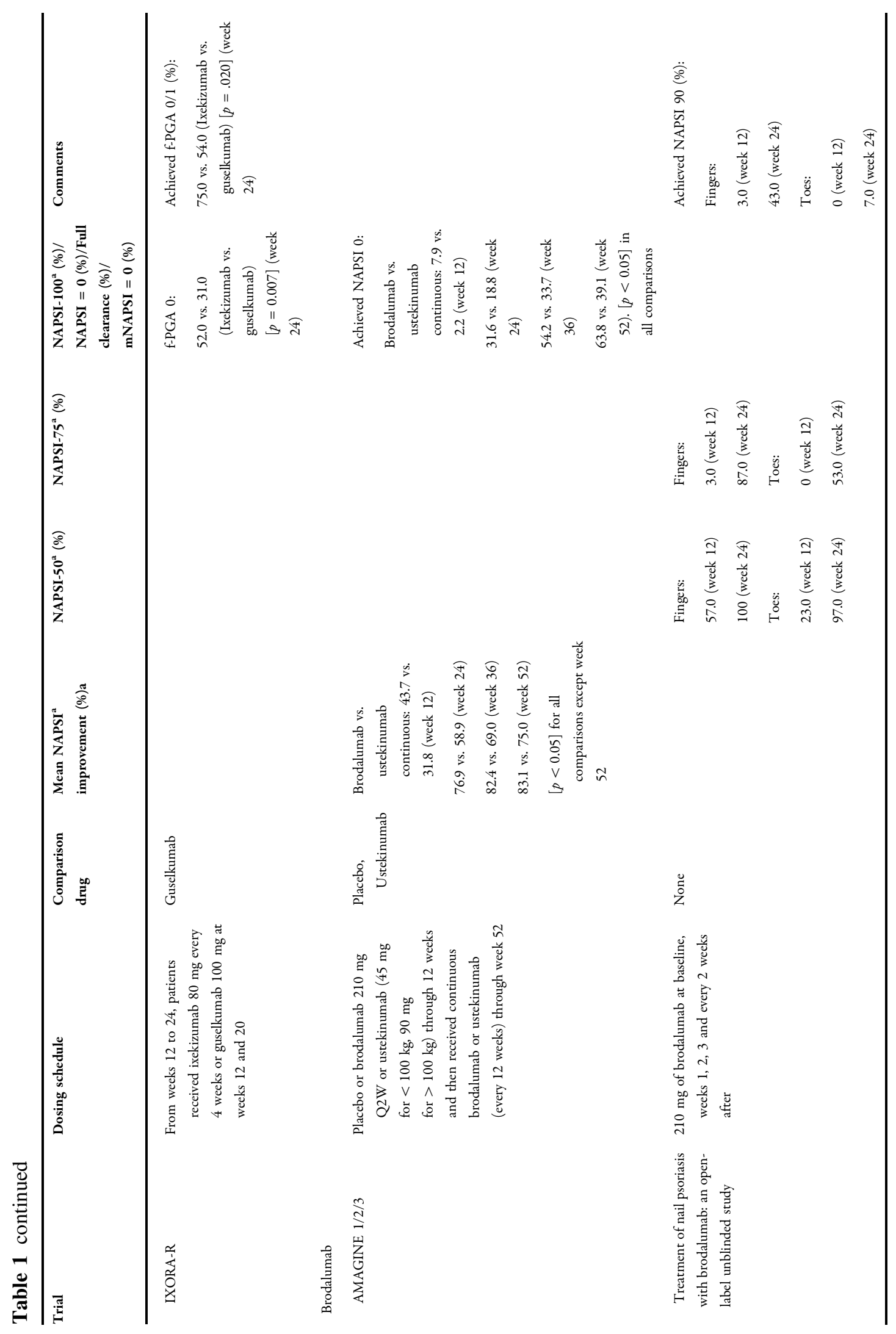




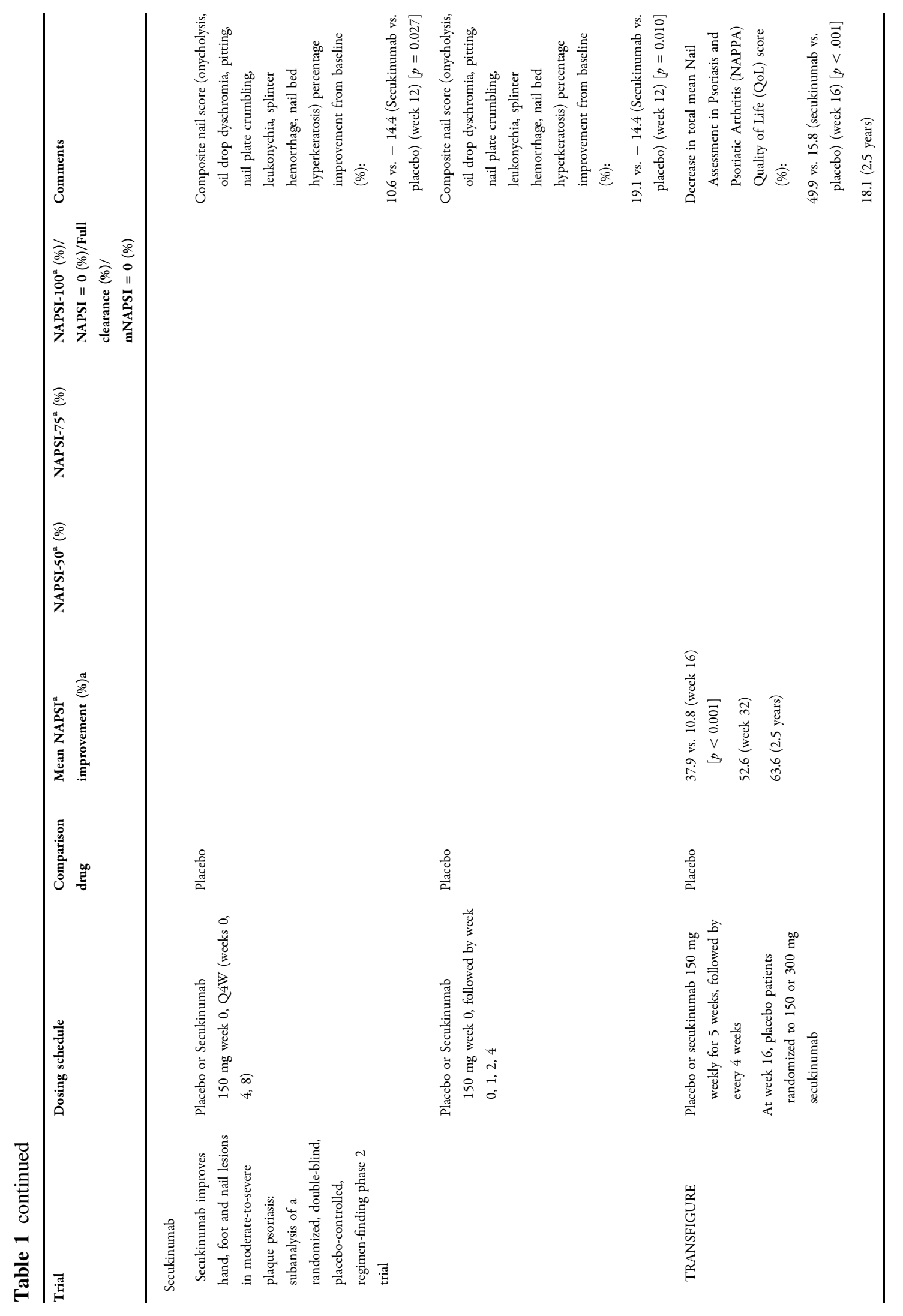




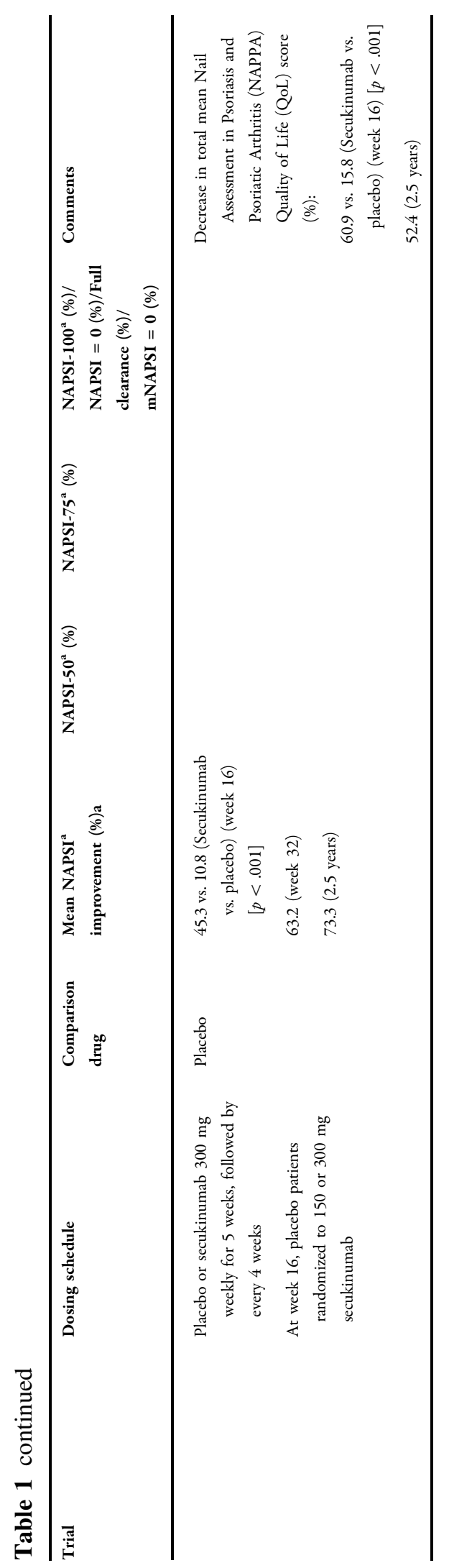




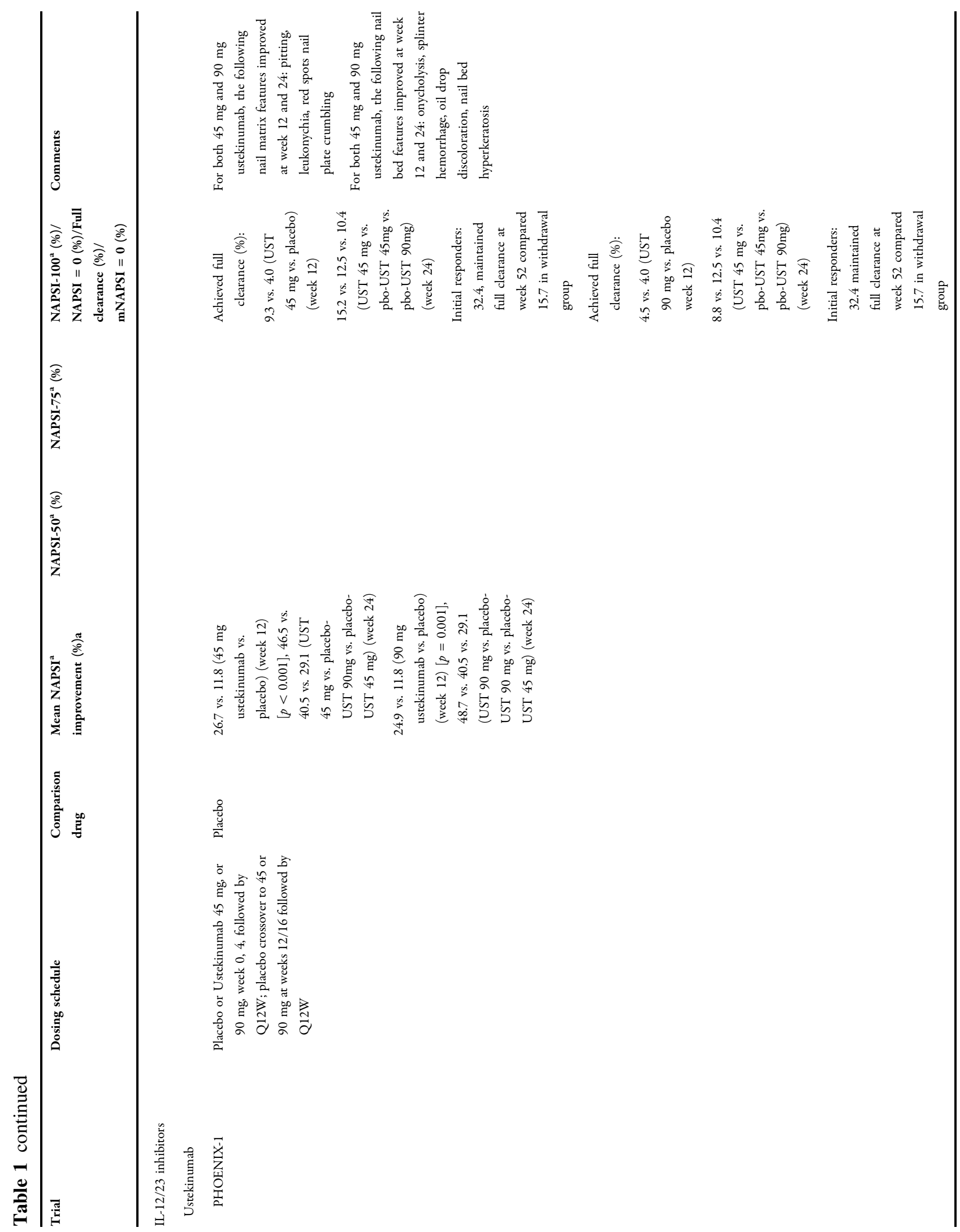




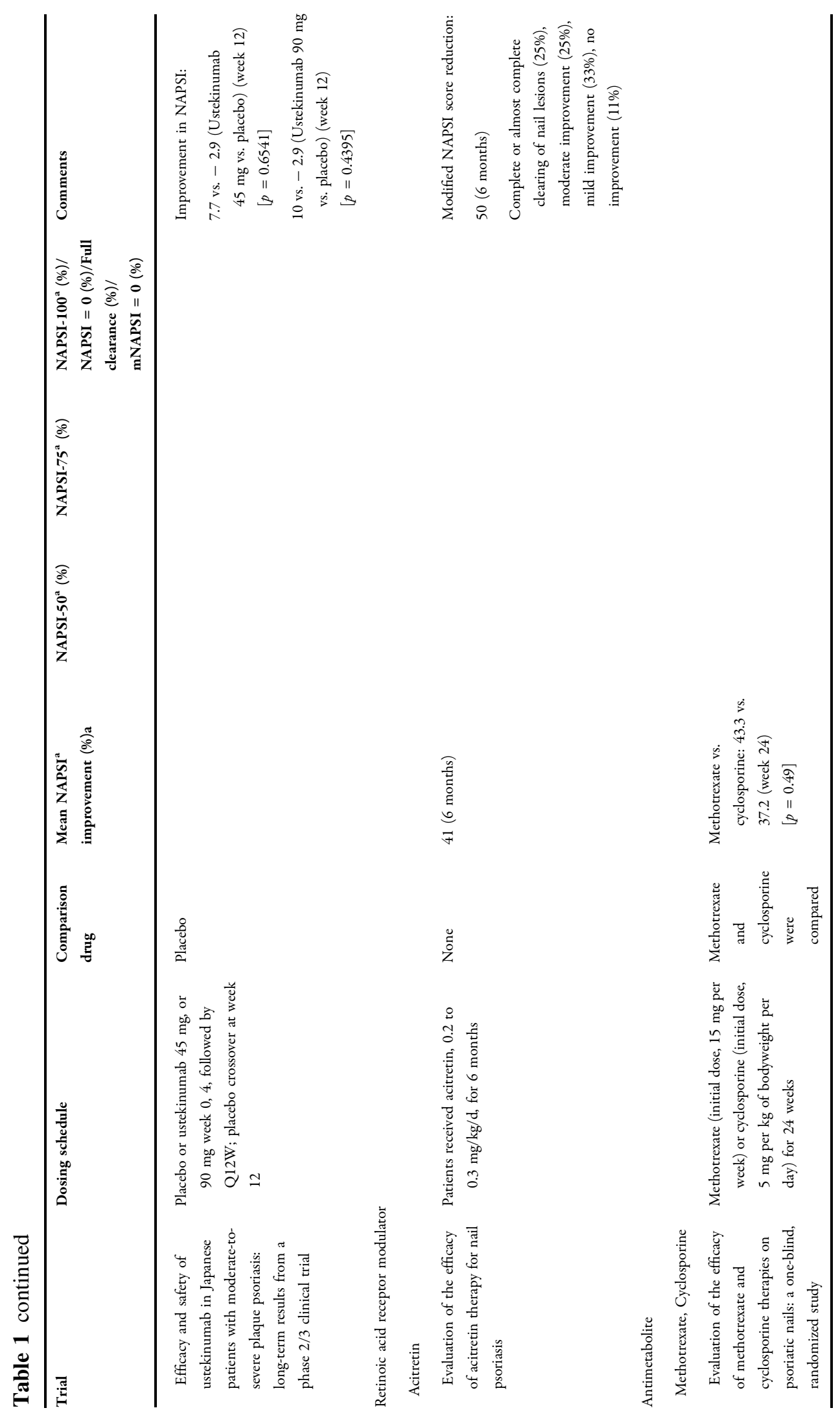




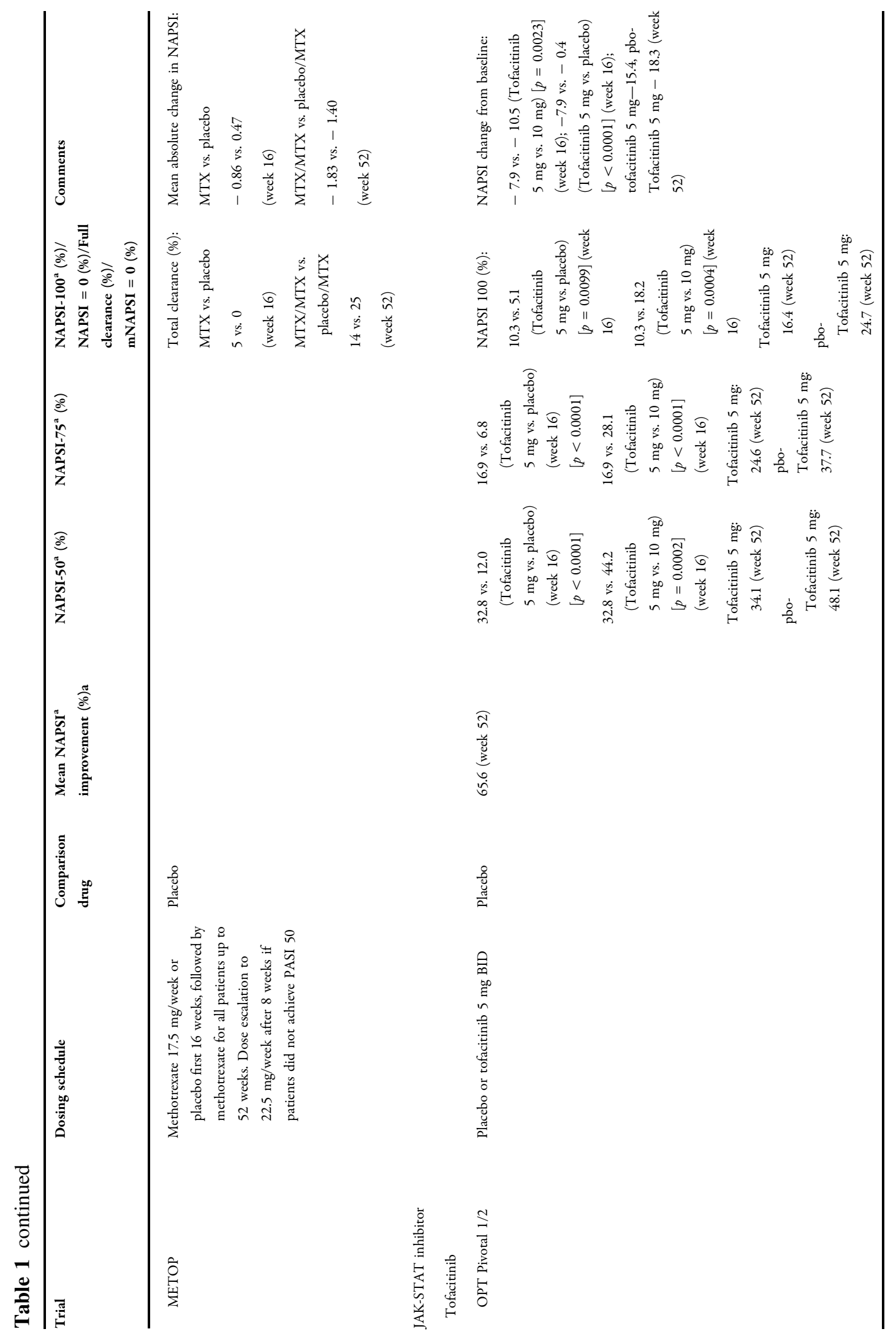




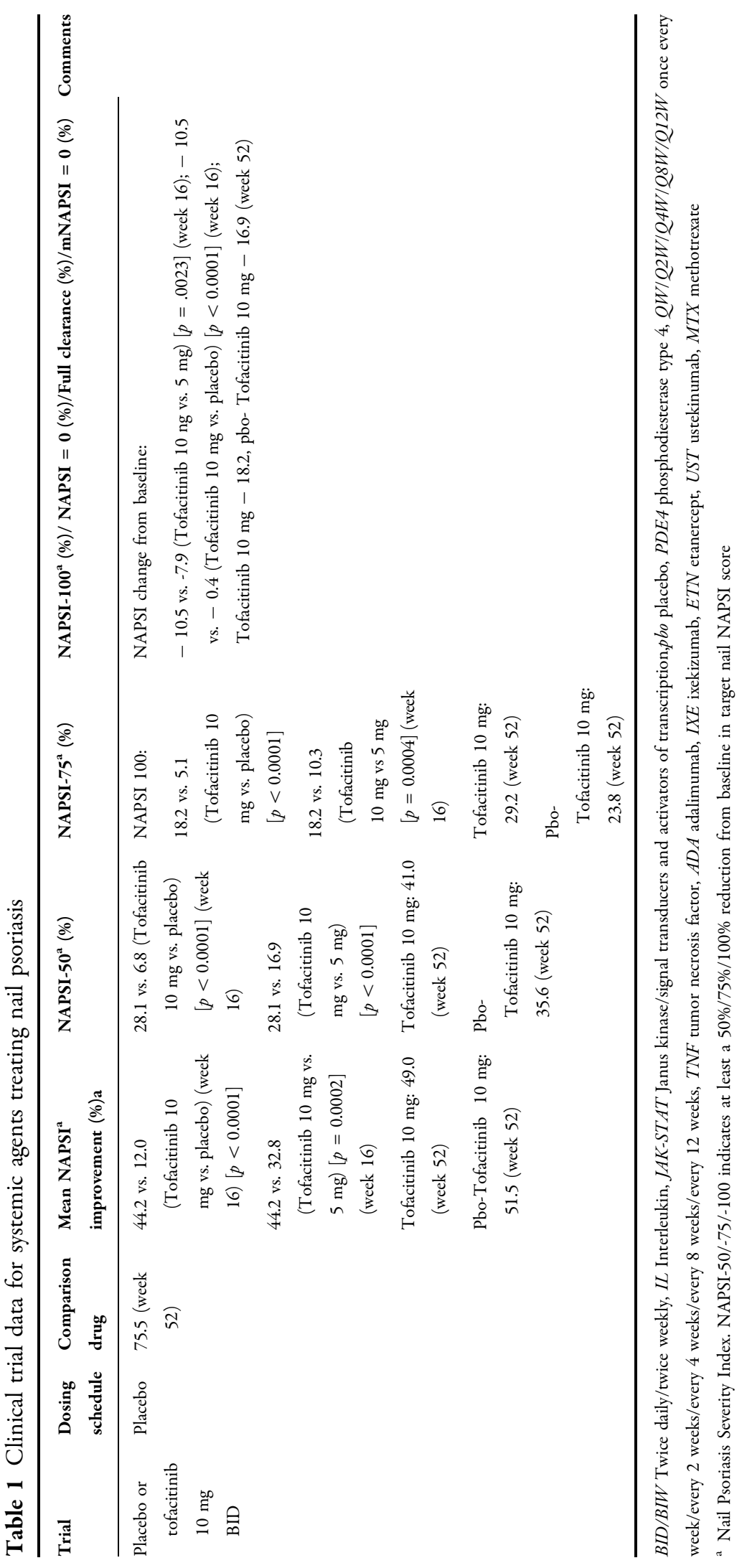


and 2, respectively. Patients who were re-randomized from placebo to apremilast $30 \mathrm{mg}$ at week 16 showed improvement in mean NAPSI percentage change at week 32 (24.6 and 47.6\% in ESTEEM 1 and 2, respectively). Through week 52, patients in ESTEEM 1 and 2 who had a Psoriasis Area Severity Index (PASI) response at week 32 (ESTEEM 1: $\geq 75 \%$ reduction from baseline/ESTEEM 2: $\geq 50 \%$ reduction from baseline) continued to show improvement in nail psoriasis at week 52 . The mean percentage reduction from baseline in target nail NAPSI score for these patients, who either received apremilast $30 \mathrm{mg}$ initially or were re-randomized from placebo to apremilast at week 32 ranged from 60 to $64 \%$. The LIBERATE study also demonstrated that the benefit of apremilast can sustained as far as week $104[30,31]$.

\section{Tumor Necrosis Factor Alpha Inhibitors}

\section{Etanercept}

A 24-week randomized controlled clinical trial exploring the use of etanercept, infliximab, and adalimumab for the treatment of nail psoriasis was conducted by Ortonne et al. in 2013 [35]. The efficacy of two dosing regimens of etanercept were compared in patients who previously failed at least one systemic therapy. Patients were randomized to the etanercept group received $50 \mathrm{mg}$ twice weekly for 12 weeks followed by once weekly (BIW/QW), or $50 \mathrm{mg}$ once weekly for 24 weeks $(\mathrm{QW} / \mathrm{QW})$. The primary endpoint was the mean NAPSI over 24 weeks. At week 24, mean NAPSI had decreased in both etanercept groups [BIW/QW group: -4.3 ( $p<0.0001)$; QW/QW group: -4.4 $(p<0.0001)]$.

\section{Infliximab}

Infliximab was evaluated for the treatment of nail psoriasis in a phase III RCT conducted by Rich et al. in 2007, which followed patients for 1 year of treatment [38]. Of the 305 patients with baseline nail psoriasis, nail clearance was seen in $6.9,26.2$, and $44.7 \%$ of patients in the infliximab group at weeks 10, 24, and 50, respectively. Infliximab was superior to placebo at week 24 (26.2 vs. $5.1 ; p<0.001)$.

\section{Adalimumab}

Elewski et al. conducted a phase III randomized controlled study evaluating the efficacy and safety of adalimumab specifically for the treatment of nail psoriasis. Patients received $40 \mathrm{mg}$ adalimumab every other week or placebo, with the primary endpoint being a NAPSI-75 score (75\% reduction from baseline in NAPSI score) at week 26. The primary endpoint was met in $46.6 \%$ of patients versus $3.4 \%$ of placebo patients $(p<0.001)$ [24].

The 2013 Ortonne et al study compared the efficacy of etanercept, adalimumab, and infliximab for patients with nail psoriasis [35]. At week 14, only infliximab showed a significantly reduced mean NAPSI score from baseline $(p<0.05)$. At week 24 , all three therapies showed significantly reduced mean NAPSI scores from baseline $(p<0.05)$.

\section{Golimumab}

Golimumab is a tumor necrosis factor (TNF)alpha inhibitor approved for the treatment of rheumatoid arthritis, PsA, and ankylosing spondylitis. The GO-VIBRANT trial evaluated the efficacy of golimumab for the treatment of nail symptoms associated with PsA [57]. Patients were randomized to receive either intravenous (IV) golimumab $2 \mathrm{mg} / \mathrm{kg}$ at week 0 , 4 , and then every 8 weeks through week 52 , or placebo with crossover at week 24 . The study found that golimumab was an effective option for the treatment of nail psoriasis, achieving superior reductions in NAPSI score versus placebo at week 14 (NAPSI score: 9.6 vs. 1.9; $p<0.0001$ ) and week 24 (NAPSI score: 11.4 vs. $3.7 ; p<0.0001)$.

\section{Interleukin-23 Inhibitors}

\section{Guselkumab}

In 2018, Foley et al. compared the efficacy data of guselkumab with adalimumab and placebo from the VOYAGE 1 and 2 trials for psoriasis in specific body regions, including the nails [40]. These were double-blind, placebo-controlled trials assessing the efficacy of guselkumab versus adalimumab. Fingernail Physician Global Assessment (f-PGA) and NAPSI were included 
endpoints. At baseline, 928 (50.7\%) of the 1829 enrolled patients had a score of $\geq 2$ for f-PGA and were included in analysis. At week 16, the percentage of patients achieving f-PGA of $0 / 1$ was superior in the guselkumab group compared to the placebo group (46.7 vs. $15.2 \%$; $p<0.001)$. At week 24 , there was no statistical difference between guselkumab and adalimumab (60 vs. $64 \% ; p=0.11$ ).

\section{Interleukin-17 Inhibitors}

\section{Ixekizumab}

The 2016 phase III RCT UNCOVER-3 compared ixekizumab treatment to placebo and etanercept [43]. Patients received placebo, etanercept (50 mg twice weekly), or $80 \mathrm{mg}$ ixekizumab as one injection every 4 weeks $(\mathrm{Q} 4 \mathrm{~W})$ or every 2 weeks (Q2W) after receiving a $160 \mathrm{mg}$ starting dose. At week 12, greater mean percentage NAPSI improvements were achieved in the ixekizumab versus placebo groups and in the ixekizumab versus etanercept groups in both the Q4W group [36.7 vs. $-34.3 \%$ (vs. placebo), $p<0.001 ; 36.7$ vs. $20 \%$ (vs. etanercept), $p=0.0048$ ] and Q2W group [35.2 vs. $-34.3 \%$ (vs. placebo), $p<0.001 ; 36.7$ vs. $20 \%$ (vs. etanercept), $p=0.072]$. Here, a negative sign implies that NAPSI worsened in the placebo group. The benefit of ixekizumab in the management of nail psoriasis was also demonstrated in patients with active PsA [60].

The IXORA-R trial compared the efficacy of ixekizumab to guselkumab in the treatment of nail psoriasis [45]. From weeks 12 to 24 , patients either received ixekizumab $80 \mathrm{mg}$ Q4W or guselkumab $100 \mathrm{mg}$ at weeks 12 and 20. The results showed that ixekizumab was superior in efficacy in the treatment of nail psoriasis at week 24, as more ixekizumab-treated patients achieved an f-PGA of $0 / 1$ (75 vs. $54 \%$; $p=0.020)$.

\section{Brodalumab}

In 2020, data were published on two phase III studies (AMAGINE-2/-3) that had assessed the treatment efficacy of brodalumab in nail psoriasis. Patients received either brodalumab $210 \mathrm{mg}$ Q2W or ustekinumab continuously through 52 weeks [56]. Endpoints included mean NAPSI improvement and achievement of a NAPSI 0 score (absence of all parameters in the NAPSI). Comparison of brodalumab and ustekinumab demonstrated an improved mean NAPSI score for brodalumab: 43.7 versus 31.8 (week 12), 76.9 versus 58.9 (week 24), 82.4 versus 69 (week 36), and 83.1 versus 75 (week $52)$; of note, significance $(p<0.05)$ was cited for all comparisons with the exception of week 52 . Achievement of NAPSI 0 was the following for brodalumab compared to ustekinumab: 7.9 versus 2.2 (week 12), 31.6 versus 18.8 (week 24), 54.2 versus 33.7 (week 36), and 63.8 versus 39.1 (week 52); significance $(p<0.05)$ was obtained for all comparisons.

\section{Secukinumab}

In 2020, long-term efficacy data was published from the TRANSFIGURE trial, demonstrating sustained efficacy of secukinumab in the treatment of nail psoriasis $[46,47]$. Patients received placebo or secukinumab $150 \mathrm{mg}$ or $300 \mathrm{mg}$ weekly for 5 weeks followed by every 4 weeks. Placebo patients were re-randomized to $150 \mathrm{mg}$ or $300 \mathrm{mg}$ secukinumab and patients were followed up to 2.5 years. Mean NAPSI improvement was evaluated at weeks 16, 32, and 2.5 years. Both dosages of secukinumab demonstrated superiority to placebo at week 16 [37.9 and 45.3 vs. 10.8 (placebo); $p<0.001$ ], and efficacy was maintained at week 32 (52.6 and 63.6, respectively) and at 2.5 years (63.6 and 73.3 , respectively).

\section{Iinterleukin-12/23 Inhibitors}

\section{Ustekinumab}

The efficacy of ustekinumab in patients with psoriatic nail disease was demonstrated in the PHOENIX-1 phase III RCT [49]. Patients received ustekinumab (45 or $90 \mathrm{mg}$ ) or placebo at weeks 0 and 4 . Of a total of 766 randomized patients, 545 (71.1\%) had nail disease. At week 12, percentage improvement from baseline NAPSI was superior for both ustekinumab $45 \mathrm{mg}(26.7 \%)$ and $90 \mathrm{mg}$ (24.9\%) compared to placebo $(11.8 \% ; p<0.001)$. This progression continued into week 24 , where improvement 
from baseline NAPSI was still superior for ustekinumab $45 \mathrm{mg}$ (46.5\%) and $90 \mathrm{mg}$ (48.7\%) doses compared to placebo.

\section{Retinoic Acid Modulators}

\section{Acitretin}

In 2009, Tosti et al. evaluated the efficacy of low-dose acitretin therapy in the treatment of isolated nail psoriasis [52]. Patients received 0.2 or $0.3 \mathrm{mg} / \mathrm{kg}$ per day of acitretin for 6 months. NAPSI improvement and modified NAPSI reduction were obtained at 6 months, with scores of 41 and $50 \%$, respectively. Complete or almost complete clearing of nail lesions was achieved in $25 \%$ of patients.

\section{Antimetabolite, Interleukin-2 Inhibitors}

\section{Methotrexate, Cyclosporine}

A single blind, randomized study conducted by Gümüssel et al. evaluated the use of methotrexate and cyclosporine in patients with nail psoriasis [53]. Patients received either oral methotrexate or cyclosporine for a total of 24 weeks. The study found that both therapies were effective options. The mean percentage reduction in NAPSI for methotrexate and cyclosporine was 43.3 and $37.2 \%$, respectively $(p=0.049)$.

The METOP study evaluated the use of methotrexate $17.5 \mathrm{mg}$ or placebo once weekly for the first 16 weeks, followed by methotrexate for all patients up to week 52 [54]. Doses were escalated to $22.5 \mathrm{mg}$ per week after 8 weeks for non-responders. Total nail clearance at week 16 was greater in the methotrexate group versus placebo (5 vs. 0\%). This effect improved at week 52 in patients who remained on methotrexate $(14 \%)$ and in patients on placebo that were switched to methotrexate (25\%).

\section{Janus Kinase-Signal Transducer and Activator of Transcription Inhibitor}

\section{Tofacitinib}

Tofacitinib, a Janus kinase-signal transducer and activator of transcription (JAK-STAT) inhibitor, is another nail psoriasis therapy, which was explored in a 52-week, phase III RCT in 2017 [58]. This analysis included data from two identical studies (OPT Pivotal 1 and 2) in which patients were randomized 2:2:1 to receive tofacitinib $5 \mathrm{mg}$, tofacitinib $10 \mathrm{mg}$, or placebo twice daily. Compared to placebo, at week 16, more patients receiving tofacitinib $5 \mathrm{mg}$ and $10 \mathrm{mg}$ achieved NAPSI-50 [5 mg: 32.8 vs. $12.0 \%$; $10 \mathrm{mg}: 44.2 \%$ vs. $12.0 \%$ (both $p<0.05$ )], NAPSI-75 [5 mg: 16.9 vs. $6.8 \%$; $10 \mathrm{mg}: 28.1$ vs. $6.8 \%$ (both $p<0.05$ )], and NAPSI-100 [5 mg: 10.3 vs. $5.1 \% ; 10 \mathrm{mg}$ : 18.2 vs. $5.1 \%$ (both $p<0.05)$ ]. AEs were similar between the tofacitinib and placebo groups with some of the most commonly reported AEs being upper respiratory tract infection and headache [61].

\section{Laser Therapies}

The pulsed dye laser (PDL) has also been explored as a potential therapy for nail psoriasis in recent years, with varying results [62-66]. In a prospective study involving PDL as a monotherapy administered monthly over the course of 3 months, median improvement in overall NAPSI, nail bed NAPSI, and nail matrix NAPSI were $44.2 \% \quad(p=0.002$ compared to baseline), $50 \%$ ( $p=0.033$ compared to baseline), and $65.1 \%(p=0.024$ compared to baseline), respectively [63]. In another study, Huang et al. compared the efficacy of PDL plus topical tazarotene versus tazarotene alone (control) in psoriatic nail disease [67]. The mean decrease in modified NAPSI score from baseline to 6 months was significantly greater in the experimental arm than in the control arm.

Recently, Gregoriou et al. performed an intra-patient (left vs. right) prospective study in 20 patients with the aim to compare the efficacy of calcipotriol/betamethasone dipropionate (Cal/BD) foam with PDL for nail psoriasis over 12 weeks [68]. The mean total NAPSI score in the Cal/BD-treated nails was reduced from 7.85 (week 0$)$ to 4.4 at week $12(p<0.0001)$. Within the nail bed, the mean nail bed NAPSI score was reduced from 3.55 (week 0 ) to 1.4 at week 12 $(p<0.0001)$. In PDL-treated nails, no reduction in NAPSI score was noted in the nail bed (3.2 at week 0 and 3.2 at week 12) and the reduction in 
total NAPSI score was minimal, decreasing from 6.8 to 6.4. AEs included mild skin irritation on the nail fold in two Cal/BD-treated cases and erythema and/or petechiae in five PDL-treated cases. However, these events were transient and resolved without treatment. The study showed that Cal/BD foam had greater effectiveness than PDL in treating nail psoriasis, especially with nail bed involvement.

\section{Complementary Therapies}

Non-standard therapy using natural extracts has been explored in the treatment of nail psoriasis. Indigo naturalis extract in oil (Lindioil) is one compound that has gained particular interest and has been studied in three trials [69-71]. In a RCT conducted in 2014, participants applied 1-2 drops (0.05 mL/drop) of Lindioil to the fingernails of one hand and applied calcipotriol to the other hand twice daily for 24 weeks [70]. At week 24, Lindioil use led to significantly greater improvements compared to calcipotriol for single-hand NAPSI (shNAPSI) and modified target NAPSI (mtNAPSI) scores $(p<0.001)$. Additionally, there was a greater percentage reduction in shNAPSI at week 24 for Lindioil $(51.3 \%)$ compared to calcipotriol $(27.1 \%)$ $(p<0.001)$.

\section{DISCUSSION}

Nail involvement is highly prevalent in the psoriasis population, can serve as a poor prognostic factor of disease, and greatly affects the QoL of patients with psoriasis. Multiple topical and systemic medications have been studied for this condition.

\section{Practical Management of Nail Psoriasis}

Many recommendations provided by an expert group consensus were previously published in the Journal of the American Academy of Dermatology [2]. The purpose of the present review is to provide updated evidence regarding the treatment of nail psoriasis along with additional treatment recommendations based on this evidence. A treatment algorithm incorporating previous recommendations and our new findings is presented in Fig. 1.

First-line treatments for few-nail disease $(\leq 3$ nails involved) includes topicals and intralesional corticosteroid injections. Given the reported success of intralesional methotrexate in recent studies, this treatment can be considered to be first line as well. For the treatment of nail matrix involvement only, first-line therapy should be intralesional corticosteroids or methotrexate, while topical corticosteroids or vitamin $\mathrm{D} /$ corticosteroid combinations should be used for nail bed involvement only [2]. PDL has been shown to be efficacious for nail psoriasis when combined with topical therapies and represent an additional option for patients battling resistant disease. For patients interested in alternative natural therapies, indigo naturalis extract in oil (Lindioil) has been shown to be an effective treatment for nail psoriasis in a few studies.

When disease involves $>3$ nails, has extensive cutaneous and joint involvement, and has a significant impact on QoL, systemic therapies should be considered [2]. In Table 1, we provide an updated, comprehensive comparison of the efficacy of treatments with different systemic agents for nail psoriasis. Systemic and biologic agents in particular have shown efficacy in recent trials, including adalimumab (the only biologic on which nail psoriasis efficacy data are included on the FDA label), golimumab, apremilast, etanercept, certolizumab, guselkumab, infliximab, ustekinumab, brodalumab, acitretin, secukinumab, ixekizumab, methotrexate, cyclosporine, and tofacitinib. Although data are limited, the head-tohead trials suggest that some biologics may be more efficacious than others in the treatment of nail psoriasis. Brodalumab was shown to be more effective than ustekinumab at weeks 12 , 24, 36, and 52 [56]. IL-17 inhibitors have faster onset of action than TNF-alpha inhibitors but have similar long-term efficacy, as demonstrated by ixekizumab, which was more effective than etanercept after 12 weeks but resulted in similar long-term efficacy at week 52 [43]. Ixekizumab was also shown to be more effective than guselkumab at week 24 [45]. Infliximab 


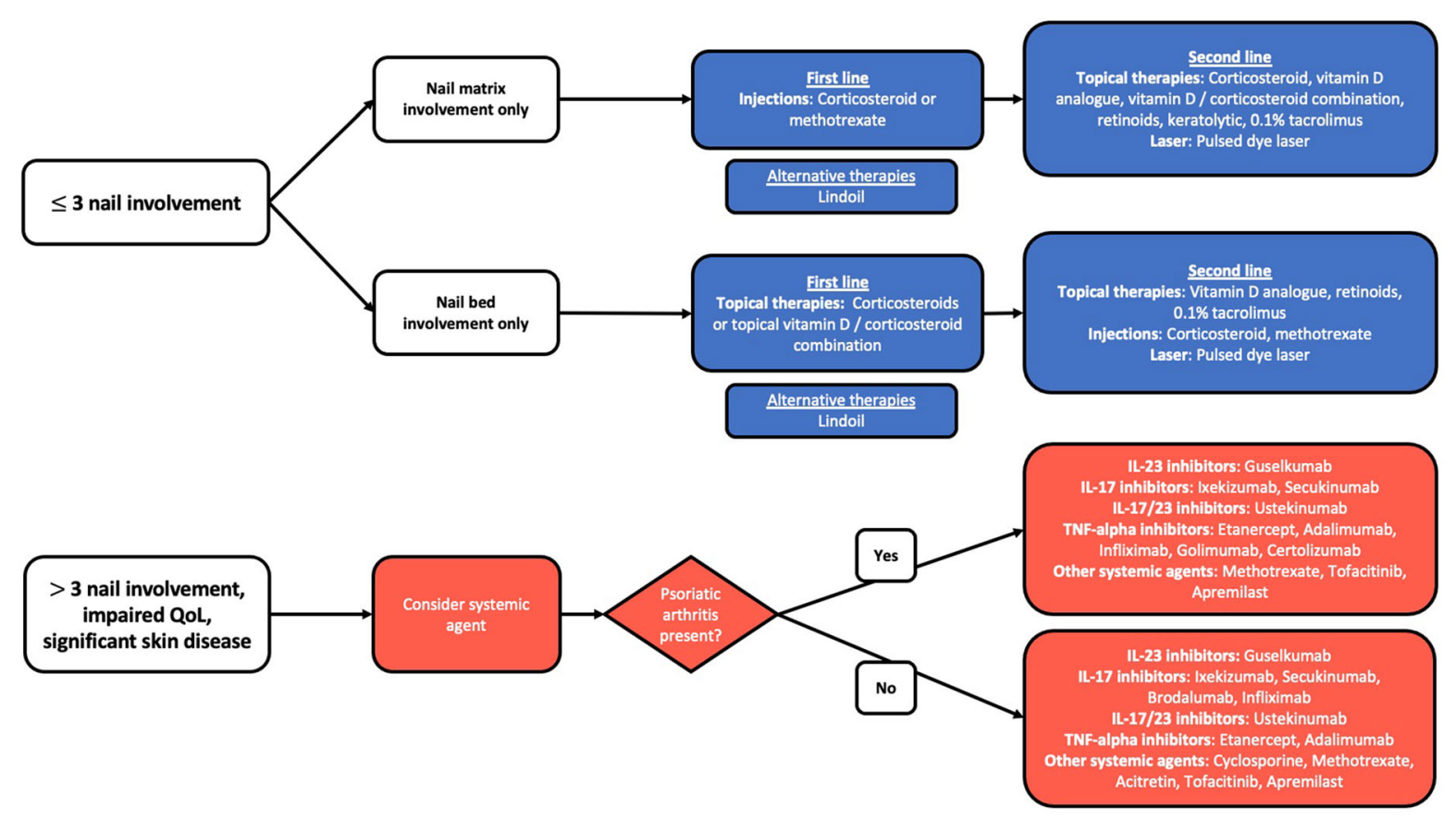

Fig. 1 Treatment algorithm for nail psoriasis. $I L$ Interleukin, $T N F$ tumor necrosis factor

was noted to have a faster onset of action when compared to etanercept and adalimumab, demonstrating that TNF-alpha inhibitors may have differing rates of action [35]. Certain IL-23 inhibitors have similar efficacy to TNF-alpha inhibitors, as guselkumab and adalimumab were found to have similar efficacy at week 24 [40].

\section{CONCLUSION}

Nail psoriasis is one of the most common special site manifestations of psoriasis. Therapy should be selected based on the extent of nail, skin, and joint involvement and the patient's QoL. Patients and providers have multiple options for therapeutic regimens, including topical corticosteroids, topical vitamin D/corticosteroid combinations, topical vitamin D analogues, local steroid injections, local methotrexate injections, PDL, Lindioil, and systemic therapies. Biologic agents have the best long-term efficacy in the treatment of nail psoriasis and multiple comparison studies have been performed on biologics. Certain IL-17 inhibitors have been shown to be superior to IL12/23 inhibitors (brodalumab vs. ustekinumab) and have superior short-term efficacy in comparison to IL-23 inhibitors (ixekizumab vs. guselkumab) and TNF-alpha inhibitors (ixekizumab vs. etanercept), although their longterm efficacy to TNF-alpha inhibitors is similar. Finally, certain TNF-alpha inhibitors have been shown to have a similar efficacy to IL-23 inhibitors (adalimumab vs. guselkumab). Based on the above data and the myriad of therapy options, treating nail psoriasis may require a personalized approach for each patient. While more studies are needed, current studies show promise in treating nail psoriasis.

\section{ACKNOWLEDGEMENTS}

Funding. No funding or sponsorship was received for this study or publication of this article. 
Authorship. All named authors meet the International Committee of Medical Journal Editors (ICMJE) criteria for authorship of this article, take responsibility for the integrity of the work as a whole, and have given their approval for this version to be published.

Authorship Contributions. Edward Hadeler contributed to the concept, design, drafting, and editing of the manuscript. Megan Mosca contributed to the drafting and editing of the manuscript. Julie Hong contributed to the drafting and editing of the manuscript. Nicholas Brownstone contributed to the editing of the manuscript. Tina Bhutani contributed to the concept and editing of the manuscript. Wilson Liao contributed to the concept, design, drafting, and editing of the manuscript. All authors discussed the results and contributed to the final manuscript.

Disclosures. Tina Bhutani has received research funding from Abbvie, Celgene, Galderma, Janssen, Pfizer, Regeneron, and Sun; and has served as an advisor for Abbvie, BoehringerIngelheim, Bristol Myers Squibb, Pfizer, Leo, Lilly, and Novartis. Wilson Liao has received research grant funding from Abbvie, Amgen, Janssen, Leo, Novartis, Pfizer, Regeneron, and TRex Bio. Edward Hadeler, Megan Mosca, Julie Hong, and Dr. Nicholas Brownstone have nothing to disclose.

Compliance with Ethical Guidelines. This article is based on previously conducted studies and does not contain any new studies with human participants or animals performed by any of the authors.

Open Access. This article is licensed under a Creative Commons Attribution-NonCommercial 4.0 International License, which permits any non-commercial use, sharing, adaptation, distribution and reproduction in any medium or format, as long as you give appropriate credit to the original author(s) and the source, provide a link to the Creative Commons licence, and indicate if changes were made. The images or other third party material in this article are included in the article's
Creative Commons licence, unless indicated otherwise in a credit line to the material. If material is not included in the article's Creative Commons licence and your intended use is not permitted by statutory regulation or exceeds the permitted use, you will need to obtain permission directly from the copyright holder. To view a copy of this licence, visit http:// creativecommons.org/licenses/by-nc/4.0/.

\section{REFERENCES}

1. Augustin M, Reich K, Blome C, Schäfer I, Laass A, Radtke MA. Nail psoriasis in Germany: epidemiology and burden of disease. Br J Dermatol. 2010;163(3):580-5. https://doi.org/10.1111/j.13652133.2010.09831.x.

2. Rigopoulos D, Baran R, Chiheb S, et al. Recommendations for the definition, evaluation, and treatment of nail psoriasis in adult patients with no or mild skin psoriasis: a dermatologist and nail expert group consensus. J Am Acad Dermatol. 2019;81(1):228-40. https://doi.org/10.1016/j.jaad. 2019.01.072.

3. Jiaravuthisan MM, Sasseville D, Vender RB, Murphy F, Muhn CY. Psoriasis of the nail: anatomy, pathology, clinical presentation, and a review of the literature on therapy. J Am Acad Dermatol. 2007;57(1):1-27. https://doi.org/10.1016/j.jaad. 2005.07.073.

4. McGonagle D, Ash Z, Dickie L, McDermott M, Aydin SZ. The early phase of psoriatic arthritis. Ann Rheum Dis. 2011;70(Suppl 1):i71-6. https://doi. org/10.1136/ard.2010.144097.

5. Tosti A, Piraccini BM, Cameli N, et al. Calcipotriol ointment in nail psoriasis: a controlled doubleblind comparison with betamethasone dipropionate and salicylic acid. Br J Dermatol. 1998;139(4): 655-9. https://doi.org/10.1046/j.1365-2133.1998. 02462.x.

6. Yamamoto T, Katayama I, Nishioka K. Topical anthralin therapy for refractory nail psoriasis. J Dermatol. 1998;25(4):231-3. https://doi.org/10. 1111/j.1346-8138.1998.tb02386.x.

7. de Jong EM, Menke HE, van Praag MC, van De Kerkhof PC. Dystrophic psoriatic fingernails treated with 1\% 5-fluorouracil in a nail penetration-enhancing vehicle: a double-blind study. Dermatology. 1999;199(4):313-8. https://doi.org/10.1159/ 000018281. 
8. Scher RK, Stiller M, Zhu YI. Tazarotene $0.1 \%$ gel in the treatment of fingernail psoriasis: a doubleblind, randomized, vehicle-controlled study. Cutis. 2001;68(5):355-8.

9. Cannavò SP, Guarneri F, Vaccaro $M$, Borgia F, Guarneri B. Treatment of psoriatic nails with topical cyclosporin: a prospective, randomized placebocontrolled study. Dermatology. 2003;206(2):153-6. https://doi.org/10.1159/000068469.

10. Rigopoulos D, Gregoriou S, Daniel Iii CR, et al. Treatment of nail psoriasis with a two-compound formulation of calcipotriol plus betamethasone dipropionate ointment. Dermatology. 2009;218(4): 338-41. https://doi.org/10.1159/000202179.

11. Márquez Balbás G, Sánchez Regaña M, Umbert MP. Tacalcitol ointment for the treatment of nail psoriasis. J Dermatolog Treat. 2009;20(5):308-10. https://doi.org/10.1080/09546630902787585.

12. Saleem K, Azim W. Treatment of nail psoriasis with a modified regimen of steroid injections. J Coll Physicians Surg Pak. 2008;18(2):78-81.

13. Choudhary P, Mehta RD, Ghiya BC, Sharma D. Treatment of nail psoriasis with intramatrical methotrexate: an uncontrolled prospective study of 20 patients. J Am Acad Dermatol. 2021;84(2):526-8. https://doi.org/10.1016/j.jaad.2020.04.159.

14. Mittal J, Mahajan B. Intramatricial injections for nail psoriasis: An open-label comparative study of triamcinolone, methotrexate, and cyclosporine. Indian J Dermatol Venereol Leprol. 2018;84(4):419. https://doi.org/10.4103/ijdvl.IJDVL_73_16.

15. Grover C, Daulatabad D, Singal A. Role of nail bed methotrexate injections in isolated nail psoriasis: conventional drug via an unconventional route. Clin Exp Dermatol. 2017;42(4):420-3. https://doi. org/10.1111/ced.13087.

16. Pasch MC. Nail psoriasis: a review of treatment options. Drugs. 2016;76(6):675-705. https://doi. org/10.1007/s40265-016-0564-5.

17. Clark A, Jellinek NJ. Intralesional injection for inflammatory nail diseases. Dermatol Surg. 2016;42(2):257-60. https://doi.org/10.1097/DSS. 0000000000000621 .

18. Kole L, Cantrell W, Elewski B. A randomized, double-blinded trial evaluating the efficacy and tolerability of vectical ointment (calcitriol $3 \mathrm{mcg} / \mathrm{g}$ ointment) when compared to betamethasone diproprionate ointment $(64 \mathrm{mg} / \mathrm{g})$ in patients with nail psoriasis. J Drugs Dermatol. 2014;13(8):912-5.

19. Nakamura RC, Abreu L de, Duque-Estrada B, Tamler C, Leverone AP. Comparison of nail lacquer clobetasol efficacy at $0.05 \%, 1 \%$ and $8 \%$ in nail psoriasis treatment: prospective, controlled and randomized pilot study. An Bras Dermatol. 2012;87(2):203-11.https://doi.org/10.1590/s036505962012000200003 .

20. De Simone C, Maiorino A, Tassone F, D'Agostino M, Caldarola G. Tacrolimus $0.1 \%$ ointment in nail psoriasis: a randomized controlled open-label study. J Eur Acad Dermatol Venereol. 2013;27(8): 1003-6. https://doi.org/10.1111/j.1468-3083.2012. 04642.x.

21. Saki N, Hosseinpoor S, Heiran A, Mohammadi A, Zeraatpishe M. Comparing the efficacy of triamcinolone acetonide iontophoresis versus topical calcipotriol/betamethasone dipropionate in treating nail psoriasis: a bilateral controlled clinical trial. Dermatol Res Pract. 2018;2018:1-7. https://doi.org/ $10.1155 / 2018 / 2637691$.

22. Boontaveeyuwat E, Silpa-Archa N, Danchaivijitr N, Wongpraparut C. A randomized comparison of efficacy and safety of intralesional triamcinolone injection and clobetasol propionate ointment for psoriatic nails. J Dermatolog Treat. 2019;30(2): 117-22. https://doi.org/10.1080/09546634.2018. 1476647 .

23. Thaçi D, Unnebrink K, Sundaram M, Sood S, Yamaguchi Y. Adalimumab for the treatment of moderate to severe psoriasis: subanalysis of effects on scalp and nails in the BELIEVE study. J Eur Acad Dermatol Venereol. 2015;29(2):353-60. https://doi. org/10.1111/jdv.12553.

24. Elewski BE, Okun MM, Papp K, et al. Adalimumab for nail psoriasis: Efficacy and safety from the first 26 weeks of a phase 3 , randomized, placebo-controlled trial. J Am Acad Dermatol. 2018;78(1):90-9. e1. https://doi.org/10.1016/j.jaad.2017.08.029.

25. Elewski BE, Baker CS, Crowley JJ, et al. Adalimumab for nail psoriasis: efficacy and safety over 52 weeks from a phase-3, randomized, placebo-controlled trial. J Eur Acad Dermatol Venereol. 2019;33(11): 2168-78. https://doi.org/10.1111/jdv.15793.

26. Poulin Y, Crowley JJ, Langley RG, Unnebrink K, Goldblum OM, Valdecantos WC. Efficacy of adalimumab across subgroups of patients with moderate-to-severe chronic plaque psoriasis of the hands and/or feet: post hoc analysis of REACH. J Eur Acad Dermatol Venereol. 2014;28(7):882-90. https://doi. org/10.1111/jdv.12198.

27. Rigopoulos D, Gregoriou S, Lazaridou E, et al. Treatment of nail psoriasis with adalimumab: an open label unblinded study. J Eur Acad Dermatol Venereol. 2010;24(5):530-4. https://doi.org/10. 1111/j.1468-3083.2009.03453.x. 
28. U.S. Food and Drug Administration. Highlights of prescribing information: Humira. https://www. accessdata.fda.gov/drugsatfda_docs/label/2020/ 125057s415lbl.pdf. Accessed 4 Dec 2020.

29. Rich P, Gooderham M, Bachelez H, et al. Apremilast, an oral phosphodiesterase 4 inhibitor, in patients with difficult-to-treat nail and scalp psoriasis: Results of 2 phase III randomized, controlled trials (ESTEEM 1 and ESTEEM 2). J Am Acad Dermatol. 2016;74(1):134-42. https://doi.org/10.1016/ j.jaad.2015.09.001.

30. Reich K, Gooderham M, Bewley A, et al. Safety and efficacy of apremilast through 104 weeks in patients with moderate to severe psoriasis who continued on apremilast or switched from etanercept treatment: findings from the LIBERATE study. J Eur Acad Dermatol Venereol. 2018;32(3):397-402. https:// doi.org/10.1111/jdv.14738.

31. Reich K, Gooderham M, Green L, et al. The efficacy and safety of apremilast, etanercept and placebo in patients with moderate-to-severe plaque psoriasis: 52-week results from a phase IIIb, randomized, placebo-controlled trial (LIBERATE). J Eur Acad Dermatol Venereol. 2017;31(3):507-17. https://doi. org/10.1111/jdv.14015.

32. Lanna C, Cesaroni GM, Mazzilli S, et al. Apremilast as a target therapy for nail psoriasis: a real-life observational study proving its efficacy in restoring the nail unit. J Dermatolog Treatment. 2020;1-5. https://doi.org/10.1080/09546634.2020.1801976.

33. Mease PJ, Fleischmann R, Deodhar AA, et al. Effect of certolizumab pegol on signs and symptoms in patients with psoriatic arthritis: 24-week results of a Phase 3 double-blind randomised placebo-controlled study (RAPID-PsA). Ann Rheum Dis. 2014;73(1):48-55. https://doi.org/10.1136/ annrheumdis-2013-203696.

34. van der Heijde D, Deodhar A, FitzGerald O, et al. 4 -year results from the RAPID-PsA phase 3 randomised placebo-controlled trial of certolizumab pegol in psoriatic arthritis. RMD Open. 2018;4(1): e000582. https://doi.org/10.1136/rmdopen-2017000582 .

35. Saraceno R, Pietroleonardo L, Mazzotta A, Zangrilli A, Bianchi L, Chimenti S. TNF- $\alpha$ antagonists and nail psoriasis: an open, 24-week, prospective cohort study in adult patients with psoriasis. Expert Opin Biol Ther. 2013;13(4):469-73. https://doi.org/10. 1517/14712598.2013.736960.

36. Ortonne JP, Paul C, Berardesca E, et al. A 24-week randomized clinical trial investigating the efficacy and safety of two doses of etanercept in nail psoriasis. Br J Dermatol. 2013;168(5):1080-7. https://doi. org/10.1111/bjd.12060.
37. Luger TA, Barker J, Lambert J, et al. Sustained improvement in joint pain and nail symptoms with etanercept therapy in patients with moderate-tosevere psoriasis. J Eur Acad Dermatol Venereol. 2009;23(8):896-904. https://doi.org/10.1111/j. 1468-3083.2009.03211.x.

38. Rich P, Griffiths CEM, Reich K, et al. Baseline nail disease in patients with moderate to severe psoriasis and response to treatment with infliximab during 1 year. J Am Acad Dermatol. 2008;58(2):224-31. https://doi.org/10.1016/j.jaad.2007.07.042.

39. Rigopoulos D, Gregoriou S, Stratigos A, et al. Evaluation of the efficacy and safety of infliximab on psoriatic nails: an unblinded, nonrandomized, open-label study. Br J Dermatol. 2008;159(2):453-6. https://doi.org/10.1111/j.1365-2133.2008.08686.x.

40. Foley P, Gordon K, Griffiths CEM, et al. Efficacy of guselkumab compared with adalimumab and placebo for psoriasis in specific body regions. JAMA Dermatol. 2018;154(6):676-83. https://doi.org/10. 1001/jamadermatol.2018.0793.

41. Langley RG, Rich P, Menter A, et al. Improvement of scalp and nail lesions with ixekizumab in a phase 2 trial in patients with chronic plaque psoriasis. J Eur Acad Dermatol Venereol. 2015;29(9):1763-70. https://doi.org/10.1111/jdv.12996.

42. Saeki H, Nakagawa H, Nakajo K, et al. Efficacy and safety of ixekizumab treatment for Japanese patients with moderate to severe plaque psoriasis, erythrodermic psoriasis and generalized pustular psoriasis: results from a 52-week, open-label, phase 3 study (UNCOVER-J). J Dermatol. 2017;44(4): 355-62. https://doi.org/10.1111/1346-8138.13622.

43. van de Kerkhof P, Guenther L, Gottlieb AB, et al. Ixekizumab treatment improves fingernail psoriasis in patients with moderate-to-severe psoriasis: results from the randomized, controlled and openlabel phases of UNCOVER-3. J Eur Acad Dermatol Venereol. 2017;31(3):477-82. https://doi.org/10. $1111 /$ jdv. 14033 .

44. Dennehy EB, Zhang L, Amato D, Goldblum O, Rich $P$. Ixekizumab is effective in subjects with moderate to severe plaque psoriasis with significant nail involvement: results from UNCOVER 3. J Drugs Dermatol. 2016;15(8):958-61.

45. Blauvelt A, Leonardi C, Elewski B, et al. A head-tohead comparison of ixekizumab vs. guselkumab in patients with moderate-to-severe plaque psoriasis: 24-week efficacy and safety results from a randomized, double-blinded trial. $\mathrm{Br} \mathrm{J}$ Dermatol. 2020;182(6):1348-58. https://doi.org/10.1111/bjd. 19509. 
46. Reich K, Sullivan J, Arenberger P, et al. Effect of secukinumab on the clinical activity and disease burden of nail psoriasis: 32-week results from the randomized placebo-controlled TRANSFIGURE trial. Br J Dermatol. 2019;181(5):954-66. https://doi.org/10. 1111/bjd.17351.

47. Reich K, Sullivan J, Arenberger P, et al. Secukinumab shows high and sustained efficacy in nail psoriasis: 2.5-year results from the randomized placebo-controlled TRANSFIGURE study. Br J Dermatol. 2021;184(3):425-36. https://doi.org/10. 1111/bjd.19262.

48. Paul C, Reich K, Gottlieb AB, et al. Secukinumab improves hand, foot and nail lesions in moderateto-severe plaque psoriasis: subanalysis of a randomized, double-blind, placebo-controlled, regimen-finding phase 2 trial. J Eur Acad Dermatol Venereol. 2014;28(12):1670-5. https://doi.org/10. $1111 /$ jdv.12359.

49. Rich $\mathrm{P}$, Bourcier $\mathrm{M}$, Sofen $\mathrm{H}$, et al. Ustekinumab improves nail disease in patients with moderate-tosevere psoriasis: results from PHOENIX 1. Br J Dermatol. 2014;170(2):398-407. https://doi.org/10. 1111/bjd.12632.

50. Youn SW, Kim BR, Cho S, et al. Determination of the Nail Psoriasis Severity Index improvement rate standards for nail psoriasis treatment in a phase IV clinical trial of ustekinumab: the MARCOPOLO study. J Eur Acad Dermatol Venereol. 2017;31(6): e298-9. https://doi.org/10.1111/jdv.14083.

51. Igarashi A, Kato T, Kato $M$, Song M, Nakagawa $H$, Japanese Ustekinumab Study Group. Efficacy and safety of ustekinumab in Japanese patients with moderate-to-severe plaque-type psoriasis: long-term results from a phase $2 / 3$ clinical trial. J Dermatol. 2012;39(3):242-52. https://doi.org/10.1111/j.13468138.2011.01347.x.

52. Tosti A, Ricotti C, Romanelli P, Cameli N, Piraccini BM. Evaluation of the efficacy of acitretin therapy for nail psoriasis. Arch Dermatol. 2009;145(3): 269-71. https://doi.org/10.1001/archdermatol. 2008.600 .

53. Gümüşel M, Özdemir M, Mevlitoğlu I, Bodur S. Evaluation of the efficacy of methotrexate and cyclosporine therapies on psoriatic nails: a oneblind, randomized study. J Eur Acad Dermatol Venereol. 2011;25(9):1080-4. https://doi.org/10. 1111/j.1468-3083.2010.03927.x.

54. Warren RB, Mrowietz U, von Kiedrowski R, et al. An intensified dosing schedule of subcutaneous methotrexate in patients with moderate to severe plaque-type psoriasis (METOP): a 52 week, multicentre, randomised, double-blind, placebo-controlled, phase 3 trial. Lancet. 2017;389(10068):
528-37. 6736(16)32127-4.

https://doi.org/10.1016/S0140-

55. Gregoriou S, Tsiogka A, Tsimpidakis A, Nicolaidou E, Kontochristopoulos G, Rigopoulos D. Treatment of nail psoriasis with brodalumab: an open-label unblinded study. J Eur Acad Dermatol Venereol. 2021;35(4):e299-301. https://doi.org/10.1111/jdv. 17055.

56. Elewski B, Rich P, Lain E, Soung J, Lewitt GM, Jacobson A. Efficacy of brodalumab in the treatment of scalp and nail psoriasis: results from three phase 3 trials. J Dermatol Treatment. 2020;0(0):1-5. https://doi.org/10.1080/09546634.2020.1749546.

57. Mease P, Elaine Husni M, Chakravarty SD, et al. Evaluation of improvement in skin and nail psoriasis in bio-naive patients with active psoriatic arthritis treated with golimumab: results through week 52 of the GO-VIBRANT study. ACR Open Rheuma. 2020;2(11):640-7. https://doi.org/10. $1002 /$ acr2.11180.

58. Merola JF, Elewski B, Tatulych S, Lan S, Tallman A, Kaur M. Efficacy of tofacitinib for the treatment of nail psoriasis: Two 52-week, randomized, controlled phase 3 studies in patients with moderate-to-severe plaque psoriasis. J Am Acad Dermatol. 2017;77(1): 79-87.e1. https://doi.org/10.1016/j.jaad.2017.01. 053.

59. Abe M, Nishigori $\mathrm{C}$, Torii $\mathrm{H}$, et al. Tofacitinib for the treatment of moderate to severe chronic plaque psoriasis in Japanese patients: Subgroup analyses from a randomized, placebo-controlled phase 3 trial. J Dermatol. 2017;44(11):1228-37. https://doi. org/10.1111/1346-8138.13956.

60. van der Heijde D, Gladman DD, Kishimoto M, et al. Efficacy and safety of ixekizumab in patients with active psoriatic arthritis: 52-week results from a phase III study (SPIRIT-P1). J Rheumatol. 2018;45(3):367-77. https://doi.org/10.3899/ jrheum.170429.

61. Papp KA, Menter MA, Abe M, et al. Tofacitinib, an oral Janus kinase inhibitor, for the treatment of chronic plaque psoriasis: results from two randomized, placebo-controlled, phase III trials. Br J Dermatol. 2015;173(4):949-61. https://doi.org/10. 1111/bjd.14018.

62. Arango-Duque LC, Roncero-Riesco M, Usero Bárcena T, Palacios Álvarez I, Fernández López E. Treatment of nail psoriasis with Pulse Dye Laser plus calcipotriol betametasona gel vs. Nd:YAG plus calcipotriol betamethasone gel: An intrapatient leftto-right controlled study. Acta Dermosifiliogr. 2017;108(2):140-4. https://doi.org/10.1016/j.ad. 2016.09.009. 
63. Peruzzo J, Garbin GC, Maldonado G, Cestari TF. Nail psoriasis treated with pulsed dye laser. An Bras Dermatol. 2017;92(6):885-7. https://doi.org/10. 1590/abd1806-4841.20175918.

64. Fernández-Guarino M, Harto A, Sánchez-Ronco M, García-Morales I, Jaén P. Pulsed dye laser vs. photodynamic therapy in the treatment of refractory nail psoriasis: a comparative pilot study. J Eur Acad Dermatol Venereol. 2009;23(8):891-95.https://doi. org/10.1111/j.1468-3083.2009.03196.x.

65. Oram Y, Karincaoğlu Y, Koyuncu E, Kaharaman F. Pulsed dye laser in the treatment of nail psoriasis. Dermatol Surg. 2010;36(3):377-81. https://doi.org/ 10.1111/j.1524-4725.2009.01448.x.

66. Treewittayapoom C, Singvahanont P, Chanprapaph $\mathrm{K}$, Haneke E. The effect of different pulse durations in the treatment of nail psoriasis with $595-\mathrm{nm}$ pulsed dye laser: a randomized, double-blind, intrapatient left-to-right study. J Am Acad Dermatol. 2012;66(5):807-12. https://doi.org/10.1016/j. jaad.2011.12.015.

67. Huang Y-C, Chou C-L, Chiang Y-Y. Efficacy of pulsed dye laser plus topical tazarotene versus topical tazarotene alone in psoriatic nail disease: a single-blind, intrapatient left-to-right controlled study. Lasers Surg Med. 2013;45(2):102-7. https:// doi.org/10.1002/lsm.22122.
68. Gregoriou S, Sidiropoulou P, Tsimpidakis A, et al. Treatment of nail psoriasis with calcipotriol/betamethasone dipropionate foam versus pulse dye laser: an unblinded, intra-patient, left-to-right prospective study. J Eur Acad Dermatol Venereol. 2020;34(9):e519-20.https://doi.org/10.1111/jdv. 16426.

69. Lin Y-K, See L-C, Chang Y-C, et al. Treatment of psoriatic nails with indigo naturalis oil extract: a non-controlled pilot study. Dermatology. 2011;223(3):239-43. https://doi.org/10.1159/ 000333362 .

70. Lin Y-K, Chang Y-C, Hui RC-Y, et al. A Chinese herb, indigo naturalis, extracted in oil (Lindioil) used topically to treat psoriatic nails: a randomized clinical trial. JAMA Dermatol. 2015;151(6):672-4. doi:https://doi.org/10.1001/jamadermatol.2014. 5460 .

71. Lin Y-K, See L-C, Huang Y-H, et al. Efficacy and safety of Indigo naturalis extract in oil (Lindioil) in treating nail psoriasis: a randomized, observerblind, vehicle-controlled trial. Phytomedicine. 2014;21(7):1015-20. https://doi.org/10.1016/j. phymed.2014.02.013. 